Article

\title{
Ethosomes for Coenzyme Q10 Cutaneous Administration: From Design to 3D Skin Tissue Evaluation
}

\author{
Maddalena Sguizzato ${ }^{1}{ }^{(}$, Paolo Mariani ${ }^{2}{ }^{\mathbb{D}}$, Francesco Spinozzi $^{2}$, Mascia Benedusi $^{3}$, \\ Franco Cervellati ${ }^{3}$, Rita Cortesi ${ }^{1, *}$, Markus Drechsler ${ }^{4}{ }^{\mathbb{D}}$, Roxane Prieux ${ }^{3}$ (D), \\ Giuseppe Valacchi ${ }^{3,5,6, *}$ and Elisabetta Esposito ${ }^{1, *}$ \\ 1 Department of Chemical and Pharmaceutical Sciences, University of Ferrara, I-44121 Ferrara, Italy; \\ sgzmdl@unife.it \\ 2 Department of Life and Environmental Sciences, Polytechnic University of Marche, I-60131 Ancona, Italy; \\ p.mariani@staff.univpm.it (P.M.); f.spinozzi@univpm.it (F.S.) \\ 3 Department of Biomedical and Specialist Surgical Sciences, University of Ferrara, I-44121 Ferrara, Italy; \\ mascia.benedusi@unife.it (M.B.); franco.cervellati@unife.it (F.C.); prxrnf@unife.it (R.P.) \\ 4 Bavarian Polymer Institute (BPI) Keylab "Electron and Optical Microscopy", University of Bayreuth, \\ D-95440 Bayreuth, Germany; Markus.Drechsler@uni-bayreuth.de \\ 5 Animal Science Department, Plants for Human Health Institute, NC Research Campus, NC State University, \\ Kannapolis, NC 28081, USA \\ 6 Department of Food and Nutrition, Kyung Hee University, Hoegi-Dong, Dongdaemun-Gu, \\ Seoul 130-701, Korea \\ * Correspondence: rita.cortesi@unife.it (R.C.); Giuseppe.valacchi@unife.it (G.V.); \\ elisabetta.esposito@unife.it (E.E.); Tel.: +39-0532-445-5482 (G.V.)
}

Received: 30 April 2020; Accepted: 18 May 2020; Published: 3 June 2020

\begin{abstract}
Ethosome represents a smart transdermal vehicle suitable for solubilization and cutaneous application of drugs. Coenzyme Q10 is an endogenous antioxidant whose supplementation can counteract many cutaneous disorders and pathologies. In this respect, the present study describes the production, characterization, and cutaneous protection of phosphatidylcholine based ethosomes as percutaneous delivery systems for coenzyme Q10. CoQ10 entrapment capacity in ethosomes was almost $100 \%$, vesicles showed the typical 'fingerprint' structure, while mean diameters were around $270 \mathrm{~nm}$, undergoing an $8 \%$ increase after 3 months from production. An ex-vivo study, conducted by transmission electron microscopy, could detect the uptake of ethosomes in human skin fibroblasts and the passage of the vesicles through $3 \mathrm{D}$ reconstituted human epidermis. Immunofluorescence analyses were carried on both on fibroblasts and 3D reconstituted human epidermis treated with ethosomes in the presence of $\mathrm{H}_{2} \mathrm{O}_{2}$ as oxidative stress challenger, evaluating 4-hydroxynonenal protein adducts which is as a reliable biomarker for oxidative damage. Notably, the pretreatment with CoQ10 loaded in ethosomes exerted a consistent protective effect against oxidative stress, in both models, fibroblasts and in reconstituted human epidermis respectively.
\end{abstract}

Keywords: ethosome; ubiquinone; $\mathrm{H}_{2} \mathrm{O}_{2}$; penetration enhancers; dermal administration; reconstituted human epidermis; small angle $\mathrm{X}$-ray scattering

\section{Introduction}

Coenzyme Q10 (CoQ10) is a lipophilic endogenous antioxidant involved in the production of cellular energy, having a key role in the mitochondria electron transport chain [1,2]. Particularly, during the aerobic cellular respiration, CoQ10 gives rise to adenosine triphosphate, thus producing cellular 
energy. In the meantime CoQ10 is reduced to ubiquinol, the form able to prevent cell membrane peroxidation [3]. Since CoQ10 tissue level decreases with aging, its supplementation is indicated in many geriatric disorders and pathologies, for instance hearing loss, diabetes, Parkinson's and cardiovascular diseases $[4,5]$. Notably, CoQ10 can be employed as adjuvant therapy in cancer patients, due to its immunostimulatory ability [6-8]. Many studies have demonstrated that the supplementation of CoQ10 can improve the antioxidant properties of skin, decreasing reactive oxygen species and thus leading to long-term anti-aging effects [9-11]. Moreover, it has been demonstrated that the cutaneous administration of CoQ10 is suitable for skin photoprotection [12-15]. Notwithstanding its beneficial role, CoQ10 administration through the skin can be problematic, due to the low drug solubility. In this regard some authors have proposed the nanoencapsulation of CoQ10 within different devices able to solubilize and deliver CoQ10 onto the skin [14-20]. For instance, polymeric or solid lipid nanoparticles, nanostructured lipid carriers, and liposomes have been investigated, suggesting their suitability for CoQ10 topical delivery. Nonetheless, to the best of our knowledge, the possibility to entrap CoQ10 within ethosomes (ETHO) has never been described. ETHO are vesicular systems whose composition is mainly based on phospholipids (e.g., phosphatidylcholine, PC), ethanol, and water $[21,22]$. ETHO can be defined as the second generation of liposome, in which the relatively high percentage of ethanol (20-45\%) makes the vesicles more stable and enables them to achieve higher drug entrapment efficiency with respect to classic liposomes [21-24]. Notably, in vitro and in vivo studies have demonstrated that ETHO possess a transdermal potential, making them suitable for enhancing absorption and bioavailability of different drugs [25-29]. The transdermal effect has been attributed to the synergistic properties of PC and ethanol, acting both as penetration enhancers. Indeed, on one hand ethanol makes the vesicle structure softer than conventional liposomes, on the other PC and ethanol exert a penetration enhancement effect [23-27]. Particularly, PC itself can promote skin permeation of actives in reason of its chemical similarity with skin lipids [30], while ethanol opens spaces within the stratum corneum, facilitating the delivery of therapeutic and cosmetic agents through the skin [31]. On this matter it is supposed that, due to their softness, ETHO can pass intact through the modified stratum corneum, while they fuse with the lipids in the deeper skin layers [21,22]. In this scenario, the possibility to achieve CoQ10 dermal/transdermal delivery by ETHO has appeared particularly appealing. Namely, the first part of the present study describes the design and characterization of CoQ10 containing ETHO, while the second part deals with an ex-vivo study aimed at investigating the behavior of CoQ10 loaded in ETHO applied on the skin. Particularly, the uptake of ETHO in primary human skin fibroblasts has been evaluated by transmission electron microscopy (TEM), while the antioxidative effect of CoQ10 has been studied by immunocytochemical analysis, evaluating the biomarker for oxidative stress 4-hydroxynonenal (4-HNE) on cells treated with $\mathrm{H}_{2} \mathrm{O}_{2}$ as oxidative stress challenger. Finally, the inhibition of the oxidative damage induced by $\mathrm{H}_{2} \mathrm{O}_{2}$ has been evaluated also on reconstituted human epidermis (RHE) treated with CoQ10 loaded ETHO.

\section{Materials and Methods}

\subsection{Materials}

Coenzyme Q10 (ubiquinone, CoQ10) was purchased from Sigma-Aldrich (St Louis, MO, USA). The soybean lecithin (PC) (90\% phosphatidylcholine) used for ETHO preparation was Epikuron 200 from Lucas Meyer, Hamburg, Germany. Solvents were HPLC grade and all other chemicals were analytical grade.

\subsection{CoQ10 Solubility Evaluation}

Solubility of CoQ10 in water, ethanol, methanol, dimethylsufoxide, and acetonitrile was determined by saturating each solvent or solvent mixture with an excess of drug. The obtained saturated solutions were mixed in an horizontal shaker $(100 \mathrm{rpm})$ in the dark for $3 \mathrm{~h}$. Afterwards 1 $\mathrm{mL}$ of samples were withdrawn and filtered through a Millex-LCR Filter, $0.45 \mu \mathrm{m}$, hydrophilic PTFE, 
25 mm (Millipore-Sigma-Aldrich Merck, Darmstadt, Germany). CoQ10 concentration was determined by reverse phase high performance liquid chromatography (RP-HPLC) analysis. HPLC analyses have been conducted using a quaternary pump (Agilent Technologies 1200 series, Santa Clara, CA, USA), a UV-detector operating at $275 \mathrm{~nm}$, and a 7125 Rheodyne injection valve with a $50 \mu \mathrm{L}$ loop. Samples have been loaded on a stainless steel C-18 reverse-phase column $(15 \times 0.46 \mathrm{~cm})$ packed with $5 \mu \mathrm{m}$ particles (Grace ${ }^{\circledR}$ - Alltima, Alltech, Bareggio, Milano, Italy). A mobile phase constituted of acetonitrile:tetrahydrofuran:water $(55: 40: 5, v / v / v)$ has been eluted at a $1 \mathrm{~mL} / \mathrm{min}$ flow rate, retention time was $5.7 \mathrm{~min}$. The method was validated for linearity $\left(R^{2}=0.995\right)$, repeatability (relative standard deviation $0.02 \%, n=6$ injections), and limit of quantification $(0.04 \mu \mathrm{g} / \mathrm{mL})$. Analyses were conducted in triplicate, mean and standard deviations values were calculated.

\subsection{Production of Ethosomes}

For the preparation of ETHO, PC $(15,30$, or $50 \% w / v)$ was dissolved in ethanol and heated up to $30 \pm 1{ }^{\circ} \mathrm{C}$ in a water bath in a closed vessel. Afterwards, twice-distilled water was slowly added to the ethanolic solution up to a final 70:30 (v/v) ratio, under continuous stirring at $700 \mathrm{rpm}$ by an IKA Eurostar digital (IKA Labortechnik Janke \& Kunkel, Staufen, Germany). Mechanical stirring was performed for $30 \mathrm{~min}$ at room temperature in the dark. In the case of CoQ10 containing ETHO (ETHO-CoQ10), CoQ10 (1 mg/mL) was added to PC ethanol solution before the addition of water.

\subsection{Characterization of Ethosomes}

\subsubsection{Cryo-Transmission Electron Microscopy (Cryo-TEM)}

Samples were vitrified as previously described [32]. Particularly a $2 \mu \mathrm{L}$ sample droplet was put on a lacey carbon filmed copper grid (Science Services, Munich) for 30 s. Subsequently, a blotting paper has been employed to remove most of the liquid, resulting in a thin film stretched over the lace holes. The specimens were instantly shock frozen by rapid immersion into liquid ethane cooled to approximately $90 \mathrm{~K}$ by liquid nitrogen in a temperature-controlled freezing unit (Zeiss Cryobox, Carl Zeiss Microscopy GmbH, Jena, Germany). All the steps of sample preparation have been conducted at controlled temperature. After freezing the specimens, the remaining ethane has been removed by blotting paper. The vitrified specimen was transferred to a Zeiss/Leo EM922 Omega EFTEM (Zeiss Microscopy GmbH, Jena, Germany) transmission electron microscope using a cryoholder (CT3500, Gatan, Munich, Germany). Sample temperature was maintained below 100K during the examination. Specimens were examined with reduced doses of about 1000-2000 e/nm $\mathrm{nm}^{2}$ at $200 \mathrm{kV}$. Images have been recorded by a CCD digital camera (Ultrascan 1000, Gatan, Munich, Germany) and analyzed using a GMS 1.9 software (Gatan, Munich, Germany).

\subsubsection{Photon Correlation Spectroscopy (PCS)}

Vesicle size analysis has been conducted using a Zetasizer Nano S90 (Malvern Instr., Malvern, England) with a $5 \mathrm{~mW}$ helium neon laser and a wavelength output of $633 \mathrm{~nm}$. Measurements were taken at $25^{\circ} \mathrm{C}$ at a $90^{\circ}$ angle and a run time of at least $180 \mathrm{~s}$. Samples have been diluted with twice distilled water in a 1:10 v:v ratio. Data were analyzed using the "CONTIN" method [33]. Measurements were performed thrice from 1 to 90 days months from ETHO production.

\subsubsection{X-ray Diffraction}

Small angle X-ray scattering (SAXS) experiments were performed at the bioSAXS beamline B21 (Diamond Light Source, Harwell, United Kingdom). CoQ10 loaded and unloaded ETHO were transferred into PCR tubes in an automated sample changer. The samples were then delivered into a temperature-controlled quartz capillary and exposed for $1 \mathrm{~s}$, acquiring 30 frames at $20{ }^{\circ} \mathrm{C}$ in order to check equilibrium conditions and to eventually monitor radiation damage. Data were collected using a Pilatus Dectris $2 \mathrm{M}$ detector with a $3.9 \mathrm{~m}$ sample-detector distance and X-ray wavelength $\lambda=1.0 \AA$. The 
explored Q-range (being $Q$ the modulus of the scattering vector, defined as $4 \pi \sin \theta / \lambda$, where $2 \theta$ is the scattering angle) extended from 0.0004 to $0.035 \mathrm{~nm}^{-1}$. 2D data were corrected for background, detector efficiency, and sample transmission were then radially averaged to derive $I(Q)$ vs. $Q$ curves [34].

\subsection{CoQ10 Content of Ethosomes}

The entrapment capacity (EC) of CoQ10 in ETHO has been determined after 1, 30, and 90 days from production of ETHO-CoQ10. Namely a $500 \mu \mathrm{L}$ sample was loaded in a centrifugal filter (Microcon centrifugal filter unit YM-10 membrane, NMWCO 10 kDa, Sigma-Aldrich, St. Louis, MO, USA) and subjected to ultracentrifugation (Spectrafuge ${ }^{\mathrm{TM}}$ 24D Digital Microcentrifuge, Woodbridge, NJ, USA) at 8,000 rpm for $20 \mathrm{~min}$. Hundred microliters of ETHO-CoQ10 in the supernatant have been diluted with ethanol $(1: 10, \mathrm{v} / \mathrm{v})$ and maintained under magnetic stirring for $30 \mathrm{~min}$ [35]. After filtration of the obtained ethanol solution by nylon syringe filters $(0.22 \mu \mathrm{m}$ pores), the amount of CoQ10 has been quantified by RP-HPLC, as above reported. The EC was determined as

$$
\mathrm{EC}=\mathrm{CoQ} 10 / \mathrm{T}_{\mathrm{CoQ} 10} \times 100
$$

where CoQ10 corresponds to the amount of drug measured by HPLC and $\mathrm{T}_{\mathrm{CoQ} 10}$ is the total amount of CoQ10 employed for ETHO production.

\subsection{Cell Culture and Cytotoxicity Studies}

Fibroblast cells (primary dermal fibroblasts isolated from skin biopsy of a healthy control subject) were grown in Dulbecco's modified Eagle's medium (DMEM) Low Glucose, supplemented with 10\% FBS, $100 \mathrm{U} / \mathrm{mL}$ penicillin, $100 \mu \mathrm{g} / \mathrm{mL}$ streptomycin and $2 \mathrm{mM} \mathrm{L}$-glutamine. Cells were incubated at $37^{\circ} \mathrm{C}$ for $24 \mathrm{~h}$ in $95 \%$ air $/ 5 \% \mathrm{CO}_{2}$ until $80 \%$ confluence. Stock solutions containing CoQ10 $(500 \mu \mathrm{M})$ were further diluted to reach the final concentrations, ranging from 1 to $41.3 \mu \mathrm{M}$. For LDH assay seeded cells were treated for $24 \mathrm{~h}$ with the different vehicles at various concentrations. Cytotoxicity was evaluated by spectrophotometric quantification of the LDH released in culture medium, using a commercial kit (Sigma-Aldrich, Merck, Darmstadt, Germany), as previously described [36,37]. For MTT assay seeded cells were exposed to the selected formulations for $24 \mathrm{~h}$, after complete removal of the treatment, $50 \mu \mathrm{L}$ of serum-free media and $50 \mu \mathrm{L}$ of MTT $(0.5 \mathrm{mg} / \mathrm{mL})$ were added and incubated for $3 \mathrm{~h}$. The MTT was reduced in living cells, forming insoluble purple formazan crystals that were then dissolved in $100 \mu \mathrm{L}$ of DMSO at $37^{\circ} \mathrm{C}$ for $15 \mathrm{~min}$. After shaking, the solution absorbance, being proportional to the number of living cells, was measured at $590 \mathrm{~nm}$, using $670 \mathrm{~nm}$ as a reference wavelength, thus converted into percentage of viability [38]. In trypan blue exclusion assay, seeded cells were treated for $24 \mathrm{~h}$ with the different vehicles at various concentrations. Afterwards, detached cells were diluted $1: 1$ with trypan blue ( $0.5 \%$ solution), then $10 \mu \mathrm{L}$ of cell suspension were applied on a Bürker Chamber for counting the living cells with an inverted microscope. The results were reported in the number of viable cells and the percentage was calculated in relation to non-treated cells, used as control ( $100 \%$ viability).

\subsection{Reconstitution of Human Epidermal Equivalents}

Human epidermal equivalents (HEEs) were reconstituted according to the CITYCARE HEE protocol from Dijkhoff et al [39]. Briefly, neonatal cells have been selected for their lack of environmental exposure, namely cells from donor of Caucasian ethnicity were preferable to limit the production of melanin. Culture of primary keratinocytes was initiated in complete KGM-Gold medium (Lonza, Walkersville, MD, USA). Before reaching confluency, proliferating keratinocytes were harvested by trypsinization, frozen, and preserved in liquid nitrogen. Third-passage proliferating keratinocytes were used for the reconstruction of the epidermis. Cell suspensions containing approximately 1 million cells were diluted in complete $\mathrm{KGM}^{\mathrm{TM}}$ Gold medium in two $75 \mathrm{~cm}^{2}$ culture flask for $10 \mathrm{~h}$ and then in EpiLife $^{\mathrm{TM}}$ (Gibco ${ }^{\mathrm{TM}}$, Life Technologies, Carlsbad, CA, USA) basal medium containing low calcium level 
$\left(60 \mu \mathrm{M} \mathrm{CaCl}_{2}\right)$ which was renewed after 2 days. When keratinocytes were subconfluent (usually on the fifth day after thawing), cells were harvested by trypsinization and centrifuged for $5 \mathrm{~min}$. The pellet was resuspended in EpiLife ${ }^{\mathrm{TM}}$ submerged medium containing $1.5 \mathrm{mM} \mathrm{CaCl}_{2}$. Polycarbonate culture inserts $\left(0.47 \mathrm{~cm}^{2}\right.$ of diffusion area and $0.4 \mu \mathrm{m}$ pore size) (Nunc ${ }^{\mathrm{TM}}$, ThermoFisher Scientific, Tustin, CA, USA) were placed in a 24-well plate containing $1.5 \mathrm{~mL}$ of pre-warmed submerged medium, using a specific carrier system (Nunc ${ }^{\mathrm{TM}}$, ThermoFisher Scientific, Tustin, CA, USA). Each insert received about $500 \mu \mathrm{L}$ of keratinocyte suspension to reach a cell density of $375.000 \mathrm{cells} / \mathrm{cm}^{2}$. After three-day incubation at $37^{\circ} \mathrm{C}$ in a humidified atmosphere containing $5 \% \mathrm{CO}_{2}$, cells were exposed to the air-liquid interface by removal of the upper compartment medium. The $1.5 \mathrm{~mL}$ of submerged medium in the lower compartment were replaced with $1.5 \mathrm{~mL}$ EpiLife $^{\mathrm{TM}}$ air-liquid interface medium containing $1.5 \mathrm{mM} \mathrm{CaCl}_{2}$, vitamin $\mathrm{C}$, and keratinocyte growth factor, and renewed every 2-3 days for 14 days.

\subsection{Transmission Electron Microscopy (TEM) Analyses}

Fibroblasts treated with ETHO for $24 \mathrm{~h}$ and non-treated cells, used as control, were grown to confluent monolayer on $10 \mathrm{~cm}$ Petri dish. RHE tissues were topically treated with ETHO for $6 \mathrm{~h}$ and non-treated RHE were used as control. Fibroblasts and RHE tissues were fixed in $2.5 \%$ glutaraldehyde in cacodylate buffer for $3 \mathrm{~h}$ at $4{ }^{\circ} \mathrm{C}$. Then fibroblasts and tissues were post-fixed in $1 \%$ osmium tetroxide for $2 \mathrm{~h}$ at $4{ }^{\circ} \mathrm{C}$, dehydrated in a graded series of alcohol, embedded in Araldite resins, and polymerized in oven for $48 \mathrm{~h}$ at $60^{\circ} \mathrm{C}$. Ultrathin sections of $60 \mathrm{~nm}$ were cut with an ultramicrotome (Ultratome Reichert SuperNova Leica, Wien, Austria), stained with uranyl acetate and lead citrate and examined in a Philips CM100 transmission electron microscope [40].

\subsection{Immunocytochemistry}

Fibroblasts were grown on coverslips at a density of $1 \times 105$ cells $/ \mathrm{mL}$, after $24 \mathrm{~h}$ of treatment with plain ETHO and ETHO-CoQ10, cells were exposed to $50 \mu \mathrm{M} \mathrm{H}_{2} \mathrm{O}_{2}$ for $1 \mathrm{~h}$. After $\mathrm{H}_{2} \mathrm{O}_{2}$ exposure, the medium was changed with fresh medium and the cells were analyzed at three different time points (i.e., directly post exposure, $2 \mathrm{~h}$ and $6 \mathrm{~h}$ post-exposure). Afterwards, cells were fixed in $4 \%$ paraformaldehyde for $10 \mathrm{~min}$ at room temperature (RT). Cells were then permeabilized for $5 \mathrm{~min}$ at RT with PBS containing $0.2 \%$ Triton X-100, then the coverslips were blocked in PBS containing $1 \%$ BSA at RT for $1 \mathrm{~h}$. Cells were then incubated with primary antibody for 4HNE (AB5605; Millipore Corporation, Burlington, MA, USA) (1.200) in PBS containing $0.5 \%$ BSA at $4{ }^{\circ} \mathrm{C}$ overnight. After washing, coverslips were incubated with appropriate secondary antibody $(1: 100)$ for $1 \mathrm{~h}$ at RT. Nuclei were stained with $1 \mu \mathrm{g} / \mathrm{mL}$ DAPI (Sigma-Aldrich, Merck, Darmstadt, Germany) for $1 \mathrm{~min}$. Coverslips were mounted onto glass slides using anti-fade mounting medium 1,4 diazabicyclooctane (DABCO) in glycerin and examined by the Leica light microscope equipped with epifluorescence at $40 \times$ magnification. Negative controls for the immunostaining experiments were performed by omitting primary antibody. Images were acquired and analyzed with Leica software [41].

\subsection{Immunohistochemistry}

RHE was topically pretreated with $50 \mu \mathrm{L}$ of ETHO-CoQ10 for $24 \mathrm{~h}$, then exposed to $200 \mu \mathrm{M} \mathrm{H}_{2} \mathrm{O}_{2}$ for $90 \mathrm{~min}$ and analyzed. Formalin-fixed paraffin-embedded (FFPE) sections were used to quantify 4-HNE expression in the RHE models with a thickness of $4 \mu \mathrm{m}$. FFPE sections were deparaffinized, rehydrated, and rinsed with water. An antigen retrieval step was performed by incubating the FFPE sections in $10 \mathrm{mM}$ citrate buffer $\mathrm{pH} 6$ at $90^{\circ} \mathrm{C}$ for $20 \mathrm{~min}$. All FFPE sections were firstly washed twice in phosphate buffer saline (PBS), then blocked for $1 \mathrm{~h}$ in PBS containing $0.2 \%$ bovine serum albumin and $0.02 \%$ Triton X-100, further incubated overnight at $4{ }^{\circ} \mathrm{C}$ with 4 -HNE antibody (AB5605, Merck Millipore, Burlington, MA, USA) (1:100). Tissue sections were washed in PBS containing $0.2 \%$ bovine serum albumin and $0.02 \%$ Triton X-100 before incubation with Donkey Anti-Goat IgG H\&L (Alexa Fluor ${ }^{\circledR} 488$; ab150129, Abcam, Cambridge, UK) (1:200) for 2h. After several washes, sections were finally stained with a diamidino-2-phenylindole dye (DAPI, Tocris Biosciences, Bristol, UK) $300 \mathrm{mM}$ 
solution for $5 \mathrm{~min}$, then washed thrice in TBS-T, a mixture of tris-buffered saline (TBS) and polysorbate 20 (aka Tween 20). Coverslips were subsequently mounted in an aqueous mounting medium (R\&D Systems, Minneapolis, MN, USA) and tissue sections observed under a fluorescence microscope (Nikon Microphot FXA microscope; Nikon Instruments, Amsterdam, Netherlands) equipped with a fluorescein isothiocyanate (FITC) filter. DAPI and FITC pictures were finally overlapped [42].

\subsection{Statistical Analysis}

Statistical differences of in vivo data have been calculated by repeated-measures analysis of variance (ANOVA) and the Bonferroni-Dunn post hoc pairwise comparison procedure. The software Prism 5.0, Graph Pad Software Inc. (La Jolla, CA, USA) has been employed. Probability values less than 0.05 have been considered significant in this study.

\section{Results}

\subsection{Solubility Study}

In order to design a nanotechnological formulation suitable for the delivery of the lipophilic CoQ10 ( $\log$ P 19.4, [43]), its solubility has been investigated in different solvents, namely water, ethanol, methanol, dimethyl sulfoxide, and acetonitrile. The drug was insoluble in almost all the solvents, while a slight solubility has been observed in ethanol, namely $0.3 \pm 0.2 \mathrm{mg} / \mathrm{mL}$. Since the addition of PC $(3 \%, w / v)$ to ethanol enabled to increase CoQ10 solubility up to $1 \mathrm{mg} / \mathrm{mL}$, the inclusion of the drug in ETHO vesicles has appeared the most appropriate strategy.

\subsection{Preparation and Characterization of Ethosomes}

PC is a natural amphiphilic molecule widely employed for its emulsifying properties. In addition, PC can self-organize in bilayers in excess water, giving rise to supra-molecular structures, such as direct and inverted micelles; hexagonal, cubic, and lamellar phases; as well as stable vesicles. Thus, the addition of water to PC ethanol solution under stirring spontaneously led to ETHO, appearing as milky homogeneous dispersions [44]. Different PC concentrations have been considered in order to select the ETHO composition, namely a preformulation study has been conducted investigating the influence of PC 0.6, 0.9, and $1.5 \%$ w/w on ETHO size, as reported in Table 1 and Figure 1.

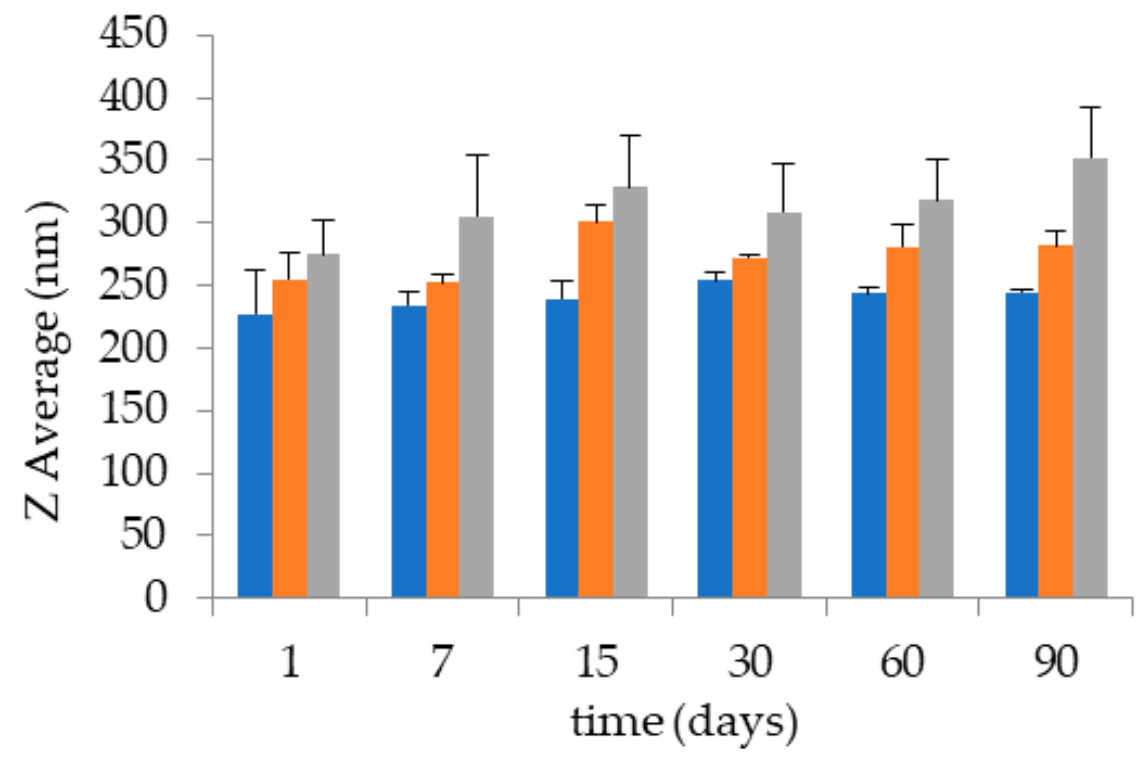

Figure 1. Effect of PC concentration on the stability of $\mathrm{ETHO}_{0.6}$ (orange), $\mathrm{ETHO}_{0.9}$ (blue), and $\mathrm{ETHO}_{1.5}$ (grey). Diameters were measured by PCS and expressed as Z average. 
It was found that both ETHO opalescence and mean diameter increased with the increasing of PC concentration, particularly ETHO mean diameters, measured by PCS, were comprised between 227 and $274 \mathrm{~nm}$. Notably, ETHO size distribution was homogeneous, being characterized always by one peak, as indicated by the intensity distribution and by the low dispersity indexes (Table 2). ETHO size variation has been investigated by time, in order to gain information on their stability. After 3 months from ETHO preparation, ETHO size was almost stable, displaying an increase of 17, 27 and $78 \mathrm{~nm}$ (i.e., 7,10 , and $28 \%$ ), respectively for PC $0.6,0.9$, and $1.5 \% w / w$. Thus the lowest the PC concentration, the highest the size stability, as found by other authors [21].

Table 1. Composition of ethosomes

\begin{tabular}{ccccc}
\hline Ethosome & PC $^{\mathbf{1}}$ & Ethanol $\% w / w$ & CoQ10 $\% w / w$ & Water $\% w / w$ \\
\hline ETHO $_{0.6}$ & 0.6 & 29.4 & n.p. & 70.0 \\
ETHO $_{0.9}$ & 0.9 & 29.1 & n.p. & 70.0 \\
ETHO $_{1.5}$ & 1.5 & 28.5 & n.p. & 70.0 \\
ETHO-CoQ10 & 0.9 & 29.0 & 0.1 & 70.0 \\
\hline
\end{tabular}

${ }^{1}$ soy phosphatidylcholine; n.p. not present.

Table 2. Dimensional distribution parameters of ethosomes, as determined by PCS

\begin{tabular}{|c|c|c|c|c|c|}
\hline \multirow{2}{*}{ Ethosome } & \multirow{2}{*}{ Days } & \multirow{2}{*}{$\begin{array}{l}\text { Z Average } \pm \\
\text { s.d. (nm) }\end{array}$} & \multicolumn{2}{|c|}{ Typical Intensity Distribution } & \multirow{2}{*}{$\begin{array}{l}\text { Dispersity } \\
\text { Index } \pm \text { s.d. }\end{array}$} \\
\hline & & & $\mathrm{nm}$ & Area \% & \\
\hline \multirow{2}{*}{$\mathrm{ETHO}_{0.6}$} & 0 & $227.45 \pm 34.10$ & 237.55 & 100 & $0.12 \pm 0.02$ \\
\hline & 90 & $244.60 \pm 5.30$ & 242.11 & 100 & $0.14 \pm 0.03$ \\
\hline \multirow{2}{*}{$\mathrm{ETHO}_{0.9}$} & 0 & $254.73 \pm 21.0$ & 244.68 & 100 & $0.10 \pm 0.02$ \\
\hline & 90 & $282.04 \pm 10.01$ & 275.34 & 100 & $0.12 \pm 0.03$ \\
\hline \multirow{2}{*}{$\mathrm{ETHO}_{1.5}$} & 0 & $274.60 \pm 32.10$ & 266.51 & 100 & $0.13 \pm 0.02$ \\
\hline & 90 & $352.15 \pm 22.01$ & 327.53 & 100 & $0.22 \pm 0.03$ \\
\hline \multirow{2}{*}{ ETHO-CoQ10 } & 0 & $271.20 \pm 5.56$ & 277.30 & 100 & $0.14 \pm 0.01$ \\
\hline & 90 & $293.05 \pm 17.18$ & 278.42 & 100 & $0.16 \pm 0.03$ \\
\hline
\end{tabular}

Despite PC 0.6\% enabled to better control ETHO size stability, since previous studies have demonstrated that phospholipid concentration in ETHO significantly affects drug entrapment efficiency $[21,45,46]$, as a compromise, PC $0.9 \% w / w$ has been selected in order to adequately entrap CoQ10, while maintaining the vesicle size stability.

Therefore, for ETHO-CoQ10 production the drug has been solubilized in PC $0.9 \%$ w/w ethanol solution, before water addition at $22{ }^{\circ} \mathrm{C}$. This strategy, devoid of high energy input and heating, appeared particularly suitable for encapsulation of labile drugs such as CoQ10. The size analysis of ETHO-CoQ10 confirmed a unimodal size distribution also in the presence of the drug, with a $16 \mathrm{~nm}$ $(6 \%)$ increase in the vesicle mean diameter, passing from 254 to $271 \mathrm{~nm}$ (Table 2). It is noteworthy that ETHO-CoQ10 mean diameter was almost unvaried at least for 3 months, undergoing merely a $22 \mathrm{~nm}(8 \%)$ increase. Cryo-TEM analyses have been conducted to gain information on ETHO morphology. In Figure 2 are reported images of ETHO 0.9 (panel a) and ETHO-CoQ10 (panel b), clearly showing spherical vesicles. In both panels a mixed population of unilamellar, multilamellar, as well as multivesicular vesicles can be noted, particularly, a 'fingerprint-like' structure due to the presence of phospholipid bilayers, can be detected in both panels, as previously described by Touitou and Godin [47]. Notably, the presence of CoQ10 did not change the PC supramolecular organization of ETHO. 

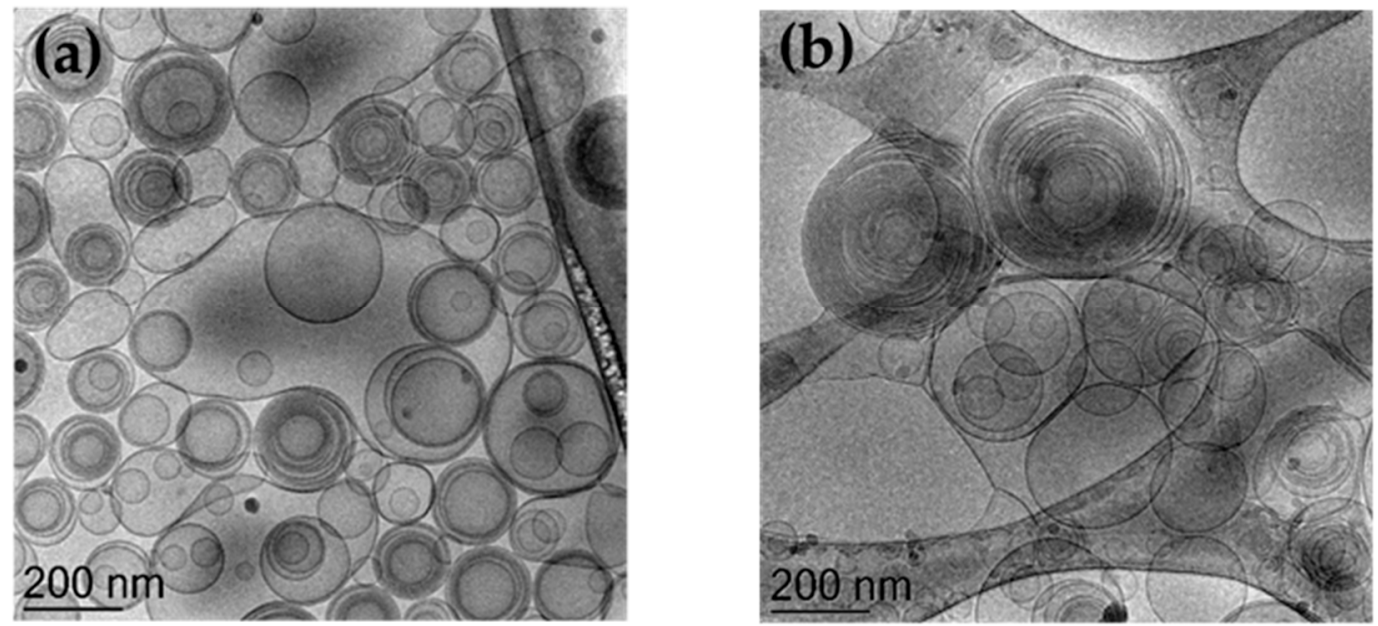

Figure 2. Cryo-transmission electron microscopy images (Cryo-TEM) of $\mathrm{ETHO}_{0.9}$ (a) and ETHO-CoQ10 (b). Bar corresponds to $200 \mathrm{~nm}$.

\section{X-ray Diffraction}

SAXS analyses have been conducted to shed light on the inner ETHO organization. Figure 3a reports the obtained scattering profiles for $\mathrm{ETHO}_{0.6}, \mathrm{ETHO}_{0.9}$ and $\mathrm{ETHO}_{1.5}$, showing a broad band $\left(\mathrm{Q} \approx 1.5 \mathrm{~nm}^{-1}\right)$ and two shoulders $\left(\mathrm{Q} \approx 0.075\right.$ and $\left.0.2 \mathrm{~nm}^{-1}\right)$. The broad band, whose position roughly corresponds to a bilayer thickness of $4.2 \mathrm{~nm}$, is indicative of the presence of PC bilayers [48,49], while the absence of distinct Bragg peaks suggests that the multilamellar vesicles are characterized by a large degree of disorder. Concerning the broad band, two points should be noticed (i) its position resulted independent of PC concentration, confirming its relationship with the bilayer electron density profile; (ii) its intensity was a linear function of the PC concentration, suggesting that the number of bilayers forming the vesicles increased with PC content. The SAXS curve of $\mathrm{ETHO}_{0.9}$ (also shown in Figure $3 b$ ) has been fitted by using a new GENFIT model [50] based on polydisperse spheres with core radius $R_{0}$ and dispersion $\xi_{\text {Ro }}$ (dispersion is described by a Schultz function [50]) surrounded by $\mathrm{N}$ bilayers. In this model, the core of the vesicle is filled with ethanol (constant electron density $\left.\rho_{\text {eth }}\right)$ and the bilayers - symmetrically constituted by three shells with constant electron densities corresponding to the polar head (thickness $R_{1}$ and electron density $\left.\rho_{1}\right)$, the aliphatic chain $\left(R_{2}\right.$ and $\left.\rho_{2}\right)$, and the terminal methyl group $\left(\mathrm{R}_{3}\right.$ and $\left.\rho_{3}\right)$ domains-are separated by water layers of thickness $\mathrm{c}$ and electron density $\rho_{0}$. Moreover, the bilayer distribution is described by the paracrystal theory [50], with distortion parameter $g_{c}$. The best fitting curve is reported in Figure $3 c$, while the fitting parameters are reported in Table 3. Notably, the number of bilayers, as well as the vesicle size, agree with the PCS and cryo-TEM results. In addition, the paracrystal distortion parameter reflects the ETHO disordered structure shown in Figure 2a.

Table 3. Fitting parameters for ethosomes, as determined by SAXS model analysis

\begin{tabular}{|c|c|c|c|c|c|c|c|c|c|c|c|c|c|c|}
\hline Ethosome & $\begin{array}{l}R_{1} \\
(\AA)\end{array}$ & $\begin{array}{l}R_{2} \\
(\AA)\end{array}$ & $\begin{array}{l}R_{3} \\
(\AA)\end{array}$ & $\begin{array}{c}\rho_{1} \\
\text { e/ } \AA^{3}\end{array}$ & $\begin{array}{c}\rho_{2} \\
\mathrm{e} / \AA^{3}\end{array}$ & $\begin{array}{c}\rho_{3} \\
\text { e/ } / \AA^{3}\end{array}$ & $N$ & $\begin{array}{c}c \\
\text { (̊) }\end{array}$ & $\mathrm{g}_{\mathrm{c}}$ & $\begin{array}{l}\text { Ro } \\
\text { (A) }\end{array}$ & $\xi_{\text {Ro }}$ & $\begin{array}{c}\rho_{\text {et }} \\
\text { e/ } \AA^{3}\end{array}$ & $\begin{array}{l}d_{\text {lip }} \\
(\AA \AA)\end{array}$ & $\begin{array}{l}R_{t o t} \\
(\AA)\end{array}$ \\
\hline & & 10 & 32 & & 00 & مح & & & & & & & 35.4 & 270 \\
\hline ETHO-CoQ10 & 6.9 & 11.9 & 1.2 & 0.42 & 0.30 & 0.29 & $9 \pm 1$ & 115 & 0.40 & 199 & 0.40 & 0.29 & 39.8 & 296 \\
\hline
\end{tabular}

SAXS: Small angle X-ray scattering; $R_{1}$ : thickness of the polar head shell; $R_{2}$ : thickness of the aliphatic chain shell; $R_{3}$ : thickness of the terminal methyl group shell; $\rho_{1}$ : electron density of the polar head shell; $\rho_{2}$ : electron density of the aliphatic chain shell; $\rho_{3}$ : electron density of the terminal methyl group shell; $N$ : number of stacked bilayers; $c$ : water layer thickness; $g_{c}$ : bilayer paracrystal distortion parameter; Ro: core radius of the spherical vesicle; $\xi_{\text {Ro }}$ : Schultz dispersion parameter; $\rho_{\text {et }}$ : ethanol electron density; $d_{\text {lip }}$, total thickness of the lipid bilayer; $R_{\text {tot }}$ vesicle total radius. Errors in $R_{\mathrm{i}}$ are $\pm 0.1 \AA$; errors in c and in $\mathrm{g}_{\mathrm{c}}$ are in the order of $10 \%$; errors in $R_{0}$ are in the order of $5 \%$; errors in $R_{\text {tot }}$ are in the order of $10 \%$. 

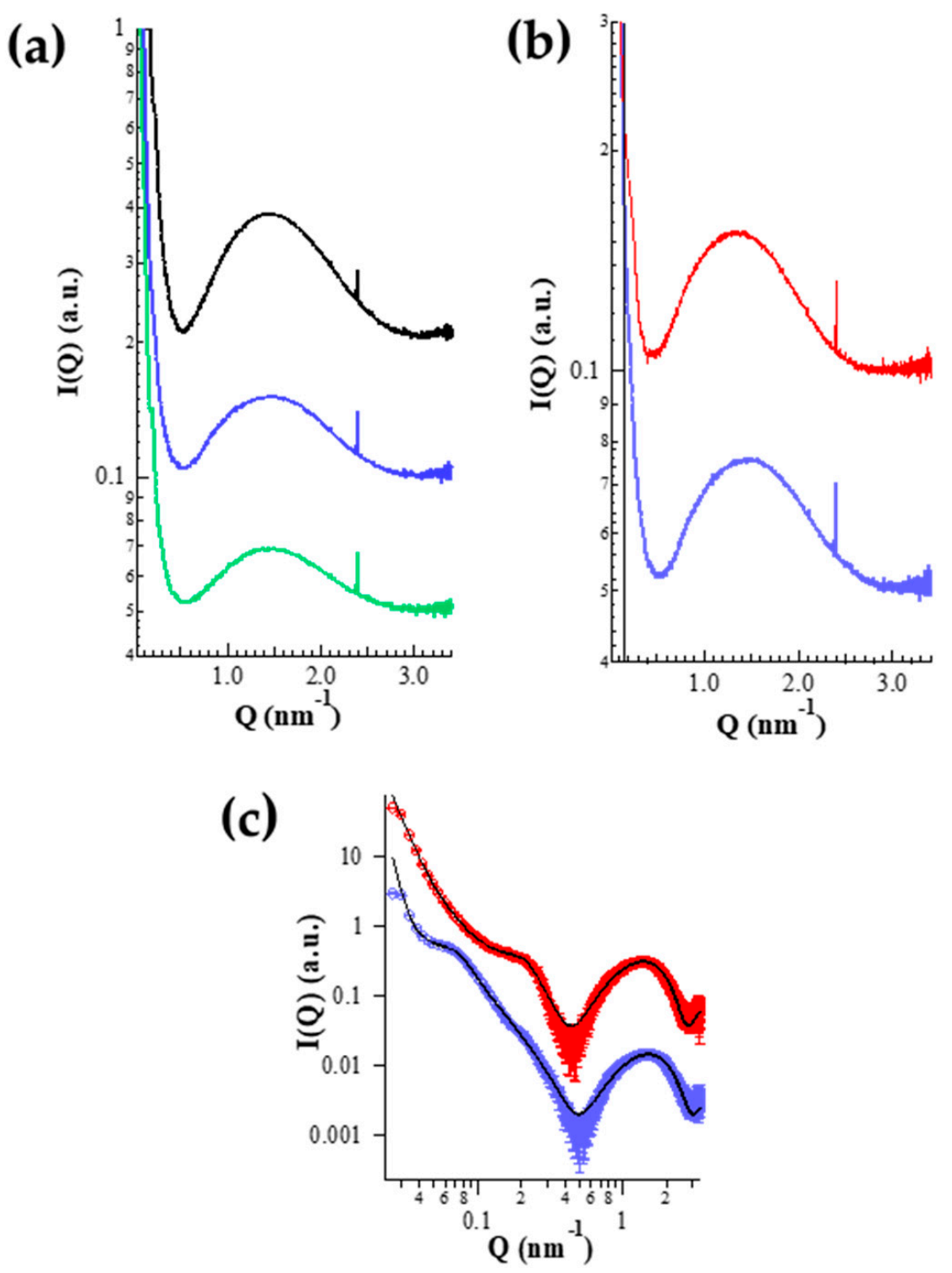

Figure 3. Small angle X-ray scattering (SAXS) profiles observed for the different ETHO samples at $25^{\circ} \mathrm{C}$. (a) $\mathrm{ETHO}_{0.6}$ (green), $\mathrm{ETHO}_{0.9}$ (blue), ETHO 1.5 (black). (b) ETHO-CoQ10 (red), ETHO 0.9 (blue). (c) Fitting analysis of the ETHO-CoQ10 (red) and $\mathrm{ETHO}_{0.9}$ (blue) curves by the new GENFIT model [50]. The continuous black lines are the best fit curves; the fitted Q-range corresponds to the length of the traced lines. In each frame, curves are scaled for clarity.

SAXS profile of ETHO-CoQ10 (Figure 3b) was similar to that of unloaded ETHO (Figure 3a), except for a shift in the position of the maximum of the broad band, moving from $1.5 \mathrm{~nm}^{-1}(4.2 \mathrm{~nm})$ to $1.38 \mathrm{~nm}^{-1}(4.6 \mathrm{~nm})$ and for the disappearance of the first shoulder at $\mathrm{Q}=0.075 \mathrm{~nm}^{-1}$. The change in the broad-band position suggests an increase of the lipid bilayer due to the CoQ10 presence, while the absence of distinct Bragg peaks confirms the disordered structure of ETHO vesicles. Model fitting results, reported in Figure $3 \mathrm{c}$ and Table 3, enabled to define at $0.4 \mathrm{~nm}$ the small enlargement of the PC bilayer, due to the dissolution of CoQ10 in the hydrocarbon lipidic region. In addition, model fitting evidenced a main supramolecular organization of multilamellar vesicles unaffected by the presence of CoQ10, as already evidenced by cryo-TEM (Figure 2b). 


\subsection{Entrapment Capacity of CoQ10 in ETHO}

The EC of CoQ10 in ETHO was almost total, namely $98 \pm 0.2 \%$ of the employed drug has been found within ETHO-CoQ10. This high EC value was expectable, indeed the preparation modalities prevented drug loss on mechanical devices, as well as thermal or light degradation. In addition many authors have demonstrated that the presence of ethanol and PC organized in multilamellar vesicles enables to increase drug loading with respect to other nanosystems [21,22,47]. As a matter of fact, it should be underlined that other authors have proposed the encapsulation of CoQ10 within nanosystems, such as solid lipid nanoparticles and liposomes. Nevertheless, ETHO were more effective, indeed EC values for CoQ10 reached at most $73 \%$ or $89 \%$ respectively in solid lipid nanoparticles and liposomes [16]. Therefore, the higher CoQ10 EC obtained by ETHO could be ascribed both to the supramolecular structure of ETHO and to the production modalities.

CoQ10 stability has been studied evaluating EC values for 3 months in ETHO-CoQ10 stored in the light at $22{ }^{\circ} \mathrm{C}$. It is noteworthy that, despite CoQ10 photo instability, EC was $90 \%$ and $60 \%$ after 30 and 90 days from production, thus higher with respect to similar studies conducted on nanostructured lipid carriers containing CoQ10 [19]. It can be hypothesized that in ETHO both phosphatidylcholine and ethanol organized in multilamellar vesicles contribute to create a strong interaction with CoQ10, controlling its degradation.

\subsection{Cytotoxicity of ETHO Containing CoQ10}

The in vitro cytotoxicity of ETHO-CoQ10 has been assessed with different concentrations of $\mathrm{ETHO}_{0.9}$ and ETHO-CoQ10 (referring to loaded CoQ10) on primary dermal fibroblasts from healthy controls, using three different techniques: trypan blue exclusion, MTT, and LDH assays. The concentration range was selected in order to confirm the safeness and biocompatibility of ETHO constituents and of the loaded drug. Figure 4 displays the results of cytotoxicity obtained with the techniques above mentioned, comparing $\mathrm{ETHO}_{0.9}$ with ETHO-CoQ10. Both formulations display similar behavior, with no cytotoxicity up to the highest concentration tested. In detail, cell viability detected by trypan blue exclusion assay (Figure $4 \mathrm{a}$ ) was higher than $90 \%$ for both $\mathrm{ETHO}_{0.9}$ and ETHO-CoQ10 for all concentrations. Moreover, MTT (Figure 4b) and LDH (Figure 4c) assays confirmed the absence of cytotoxicity, resulting in a cell viability of $82 \%$ and $89 \%$ in the case of MTT and LDH release of $11 \%$ and $13 \%$ respectively for $\mathrm{ETHO}_{0.9}$ and $\mathrm{ETHO}-\mathrm{CoQ} 10$. Hence, the encapsulated CoQ10 did not induce toxic effects on cells at all concentrations tested. Based on these data, the highest CoQ10 concentration, (i.e., $41.3 \mu \mathrm{M}$ ) has been selected for further ex-vivo experiments. 
(a)

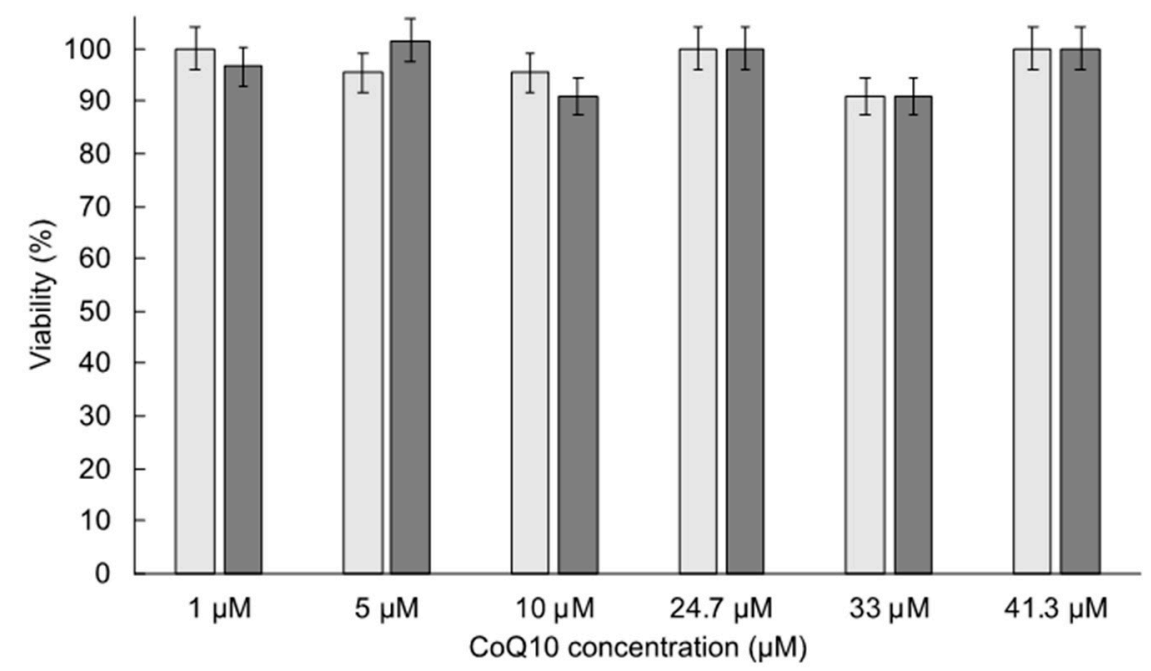

(b)

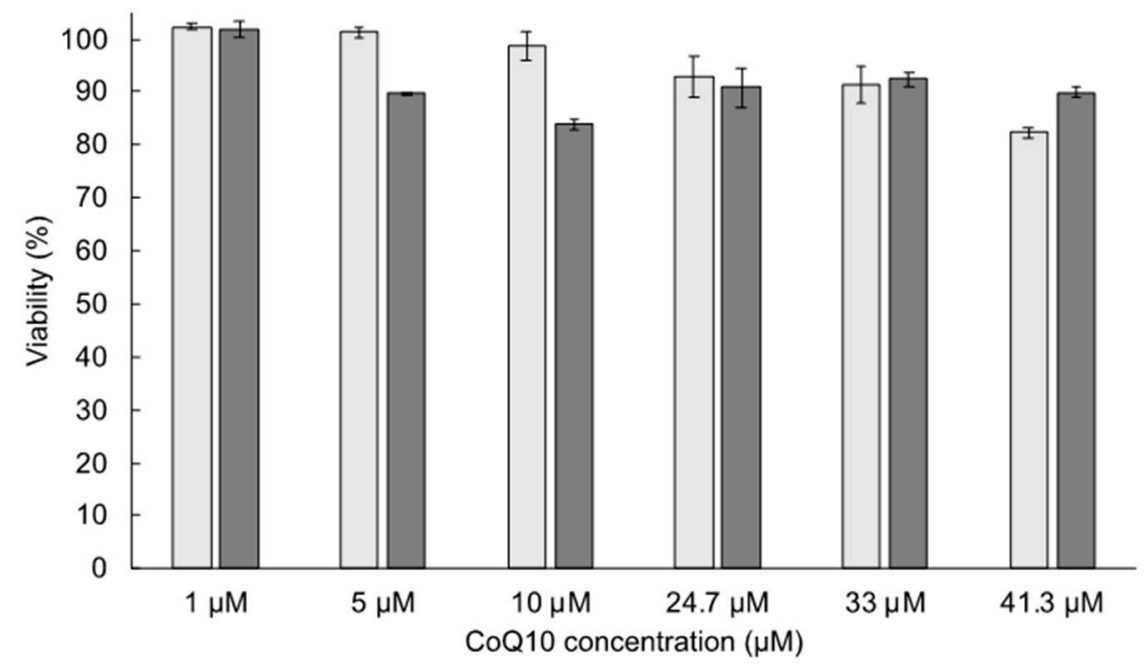

(c)

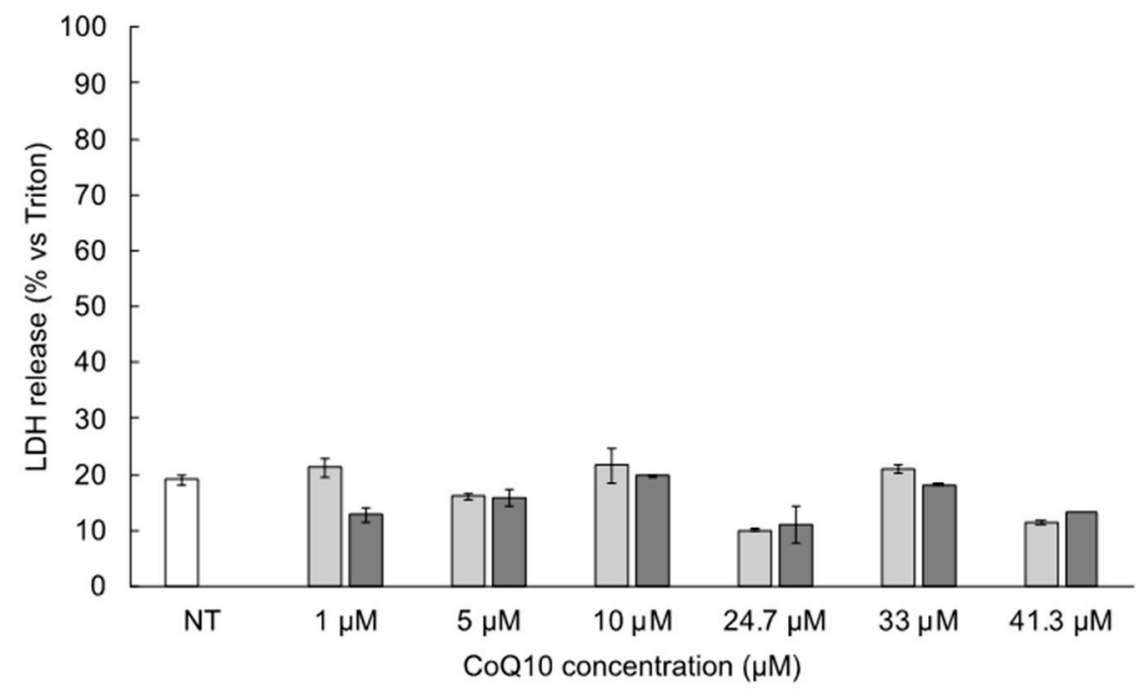

Figure 4. Cytotoxicity of $\mathrm{ETHO}_{0.9}$ (light grey) and ETHO-CoQ10 (dark grey) evaluated by trypan blue exclusion (a), MTT (b), and LDH (c) tests on primary dermal fibroblasts from healthy control subject after $24 \mathrm{~h}$ of treatment. Data are given as mean $\pm \mathrm{SD}$, representative of three independent experiments with at least three technical replicates each time. 


\subsection{ETHO Uptake in Fibroblasts Detected by TEM}

In order to investigate the uptake of $\mathrm{ETHO}_{0.9}$ in treated fibroblasts, TEM analysis was performed, comparing the ultrastructural morphology with untreated cells (Figure 5).

Focusing on cell membrane section at the two experimental conditions and at different magnifications, the passage of $\mathrm{ETHO}_{0.9}$ is clearly evidenced in panels c and d. Moreover, the involvement of endocytosis pathway could be supposed for the presence of cell membrane invaginations and vesicles within the cytoplasm. Furthermore, comparing the images with those of untreated cells, it is noteworthy that the ultrastructural morphology of fibroblasts was not affected by the presence of $\mathrm{ETHO}_{0.9}$. These findings corroborate previous studies conducted by many authors, indicating that the malleable ETHO vesicles can penetrate cellular membrane, releasing the loaded molecule within cells $[22,24,51-54]$.

Taking together the results of cytotoxicity and TEM, ETHO appeared as promising vesicle systems able to deliver the CoQ10 to the target cell, with the aim of enhancing the cellular antioxidant defense status.
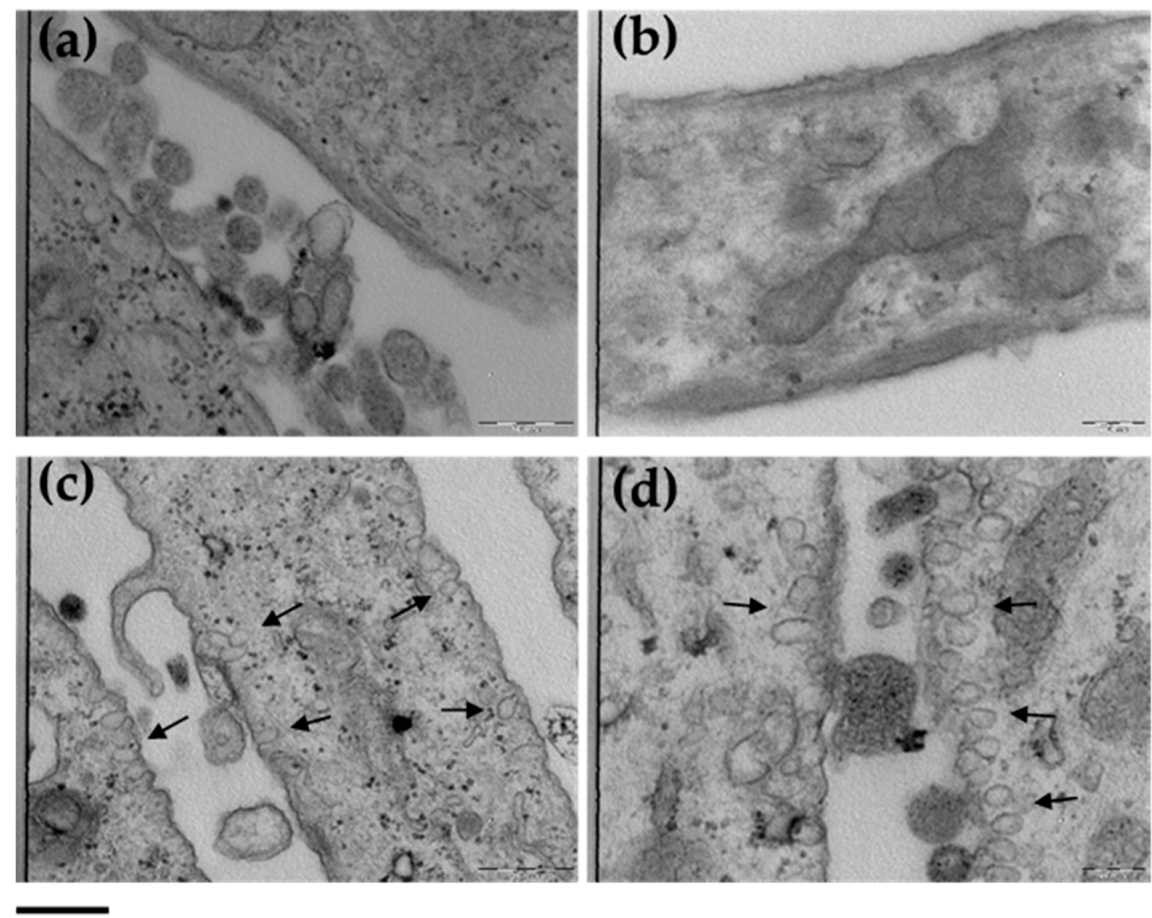

Figure 5. TEM images of control cells (a,b) and cells treated with $\mathrm{ETHO}_{0.9}(\mathbf{c}, \mathbf{d})$. Images of panels (a) and (c) refer to $31.5 \mathrm{~K}$ magnification; images of panels (b) and (d) refer to $50 \mathrm{~K}$ magnification. Arrows indicate the presence of $\mathrm{ETHO}_{0.9}$. Bar corresponds to $500 \mathrm{~nm}$.

\subsection{Evaluation of 4HNE Protein Adducts Levels in Fibroblasts Treated with ETHO-CoQ10}

The ability of ETHO-CoQ10 in protecting cells against oxidative insults has been investigated by immunocytochemical analysis for $4 \mathrm{HNE}$ protein adducts on human health fibroblasts treated with $\mathrm{H}_{2} \mathrm{O}_{2}$, as an inducer of oxidative stress. $4 \mathrm{HNE}$ is an electrophilic $\alpha, \beta$-unsaturated aldehyde, a reactive lipid mediator generated from oxidative stress-induced lipid peroxidation [55]. Briefly, untreated cells (CTRL), cells treated with $\mathrm{ETHO}_{0.9}$ and cells treated with ETHO-CoQ10 $41.3 \mu \mathrm{M}$ have been exposed to $\mathrm{H}_{2} \mathrm{O}_{2} 50 \mu \mathrm{M}$ for $1 \mathrm{~h}$. $4 \mathrm{HNE}$ protein adducts levels have been evaluated immediately after $\mathrm{H}_{2} \mathrm{O}_{2}$ exposure (T0 h), or 2 (T2h) and 6 (T6 h) h post-exposure. 4 HNE protein adducts were analyzed by immunofluorescence (Figure 6a) and quantified with respect to untreated cells (Figure 6b). Comparing the results with those of cells not subjected to oxidative insult (data not shown), the exposure to $\mathrm{H}_{2} \mathrm{O}_{2}$ induced a significant increase in $4 \mathrm{HNE}$ protein adducts formation (green fluorescence), in CTRL and cells treated with $\mathrm{ETHO}_{0.9}$ cells (Figure 6a). On the other hand, when cells exposed to $\mathrm{H}_{2} \mathrm{O}_{2}$ were 
pre-treated with ETHO-CoQ10, the formulation was able to counteract the formation of $4 \mathrm{HNE}$ protein adducts, as indicated by the reduction in green fluorescence signal intensity (Figure 6a). As displayed in Figure 6b, after $\mathrm{H}_{2} \mathrm{O}_{2}$ exposure, the levels of $4 \mathrm{HNE}$ protein adducts in ETHO-CoQ10 treated cells were maintained around 30\% even $6 \mathrm{~h}$ post-exposure, while the production of $4 \mathrm{HNE}$ adducts increased significantly over time in the untreated cells. This result agrees well with the TEM evidence, suggesting that ETHO-CoQ10 - penetrated intact within fibroblasts—can exert antioxidative potential, protecting cells against oxidative stress [56].

(a)

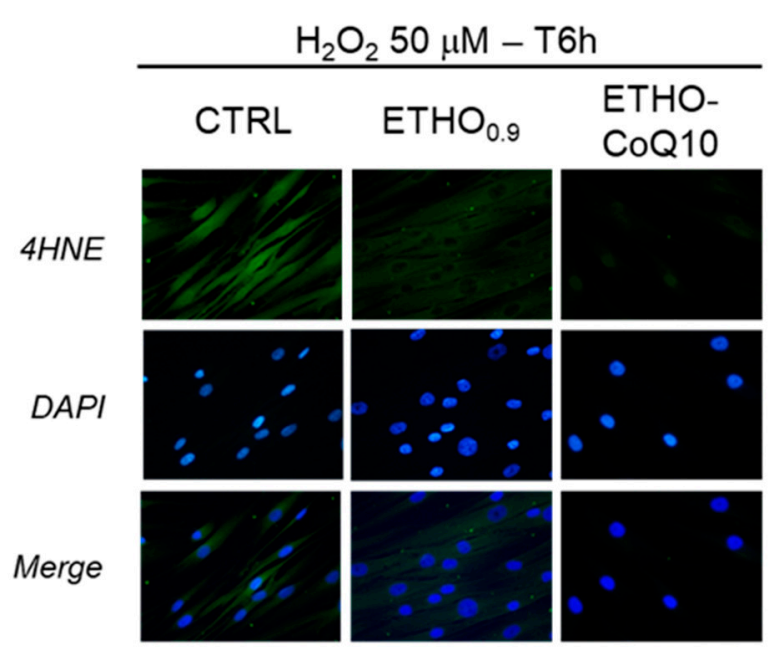

(b)

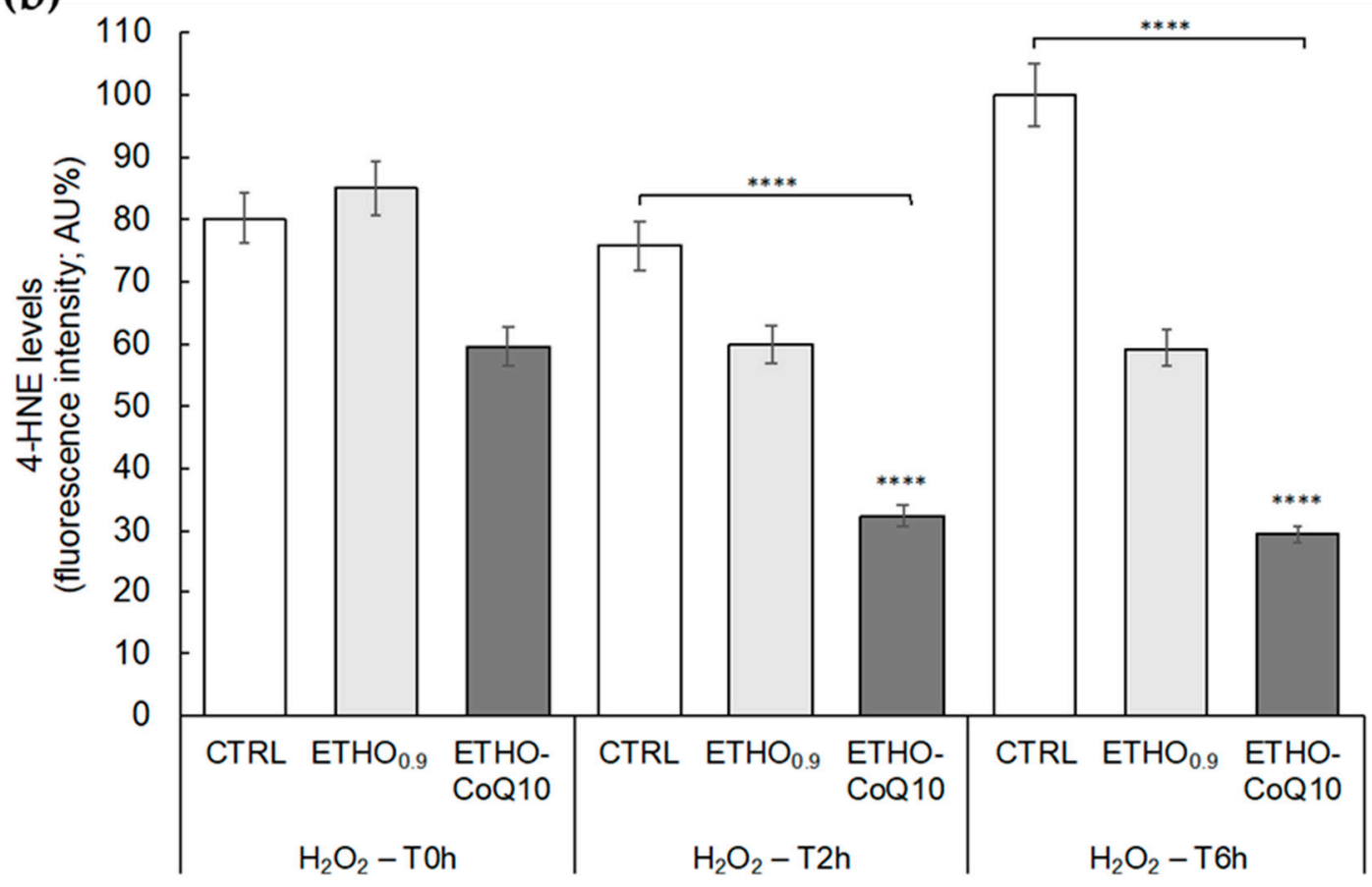

Figure 6. (a) Representative immunocytochemical images of $4 \mathrm{HNE}$ protein adducts in primary dermal fibroblasts without treatment (CTRL), treated with $\mathrm{ETHO}_{0.9}$ or ETHO-CoQ10, $6 \mathrm{~h}$ after exposure with $50 \mu \mathrm{M}$ of $\mathrm{H}_{2} \mathrm{O}_{2}$ for $1 \mathrm{~h}$. Images were taken at $40 \times$. (b) Quantification of immunofluorescence staining for $4 \mathrm{HNE}$ immediately after $\mathrm{H}_{2} \mathrm{O}_{2}$ exposure ( $\mathrm{T} 0 \mathrm{~h}$ ) or 2 ( $\mathrm{T} 2 \mathrm{~h}$ ) and $6 \mathrm{~h}$ ( $\mathrm{T} 6 \mathrm{~h}$ ) post-exposure. Data were normalized with respect to the CTRL sample treated for $6 \mathrm{~h}$ and expressed as arbitrary units \pm SD. $* * * * p \leq 0.0001$ vs. CTRL T0 h. 


\subsection{ETHO Skin Uptake in Reconstituted Human Epidermis (RHE) Detected by TEM}

It is well-known that the complex structure of the skin acts a barrier and limits the passage of lipophilic molecules. Particularly, the outermost epidermal layer, the stratum corneum (SC), is the main hurdle for the substance passage to the deeper skin layers [57]. In this regard, RHE can represent a 3D model suitable for mimicking the human epidermis morphology and physiology, even after topical application of compounds [58]. Therefore, RHE was chosen to investigate the ability of ETHO in crossing the epidermal layers. Particularly, after topical treatment with $\mathrm{ETHO}_{0.9}$ for $6 \mathrm{~h}, \mathrm{RHE}$ ultrastructural morphology has been detected by TEM (Figure 7). Figure $7 \mathrm{~b}$ shows the presence of ETHO vesicles in the epidermal layers, clearly detectable as compared to untreated RHE taken as control (Figure 7a). The images confirmed that ETHO vesicles are able to pass through the SC cells of the RHE model.
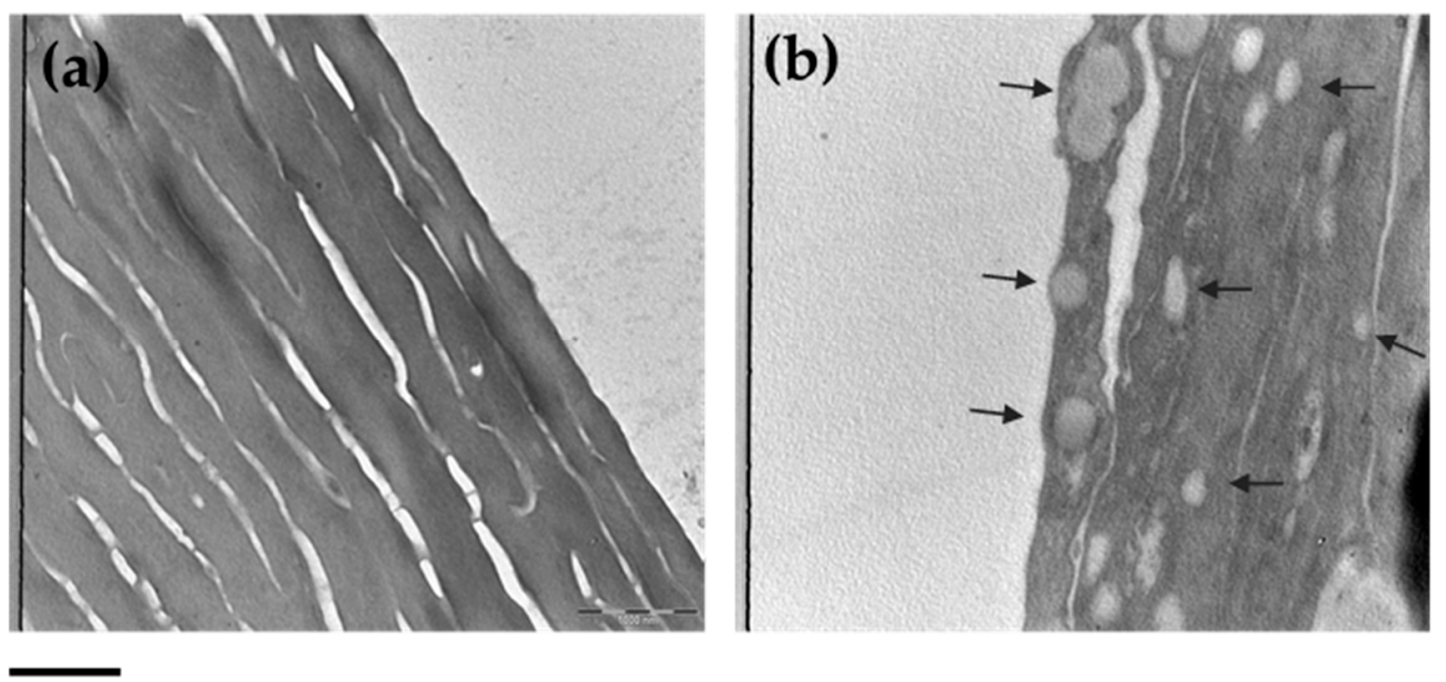

Figure 7. TEM images of control RHE (a) and RHE after $6 \mathrm{~h}$ of treatment with $\mathrm{ETHO}_{0.9}(\mathbf{b})$. Images refer to $20 \mathrm{~K}$ magnification. Arrows indicate the presence of $\mathrm{ETHO}_{0.9}$. Bar corresponds to $1000 \mathrm{~nm}$.

\subsection{Evaluation of $4 H N E$ Protein Adducts Levels in RHE Treated with ETHO-CoQ10}

In order to investigate the ability of CoQ10 loaded ETHO in protecting skin tissue against oxidative stress, an immunohistochemical analysis for $4 \mathrm{HNE}$ protein adducts has been performed on RHE treated with ETHO-CoQ10 and exposed to $\mathrm{H}_{2} \mathrm{O}_{2}$. Particularly, the effect of $\mathrm{H}_{2} \mathrm{O}_{2}$ oxidative stress was detected in RHE pretreated with ETHO-CoQ10 (ETHO-CoQ10- $\mathrm{H}_{2} \mathrm{O}_{2}-\mathrm{RHE}$ ) and compared to RHE treated with ETHO-CoQ10 and not exposed to $\mathrm{H}_{2} \mathrm{O}_{2}$ (ETHO-CoQ10-RHE), or to RHE exposed to $\mathrm{H}_{2} \mathrm{O}_{2}$ (CTRL- $\mathrm{H}_{2} \mathrm{O}_{2}$-RHE). 4HNE protein adducts levels have been analyzed by immunofluorescence (Figure 8a) and quantified with respect to untreated RHE (Figure 8b).

The exposure to $\mathrm{H}_{2} \mathrm{O}_{2}$ induced a significant increase in $4 \mathrm{HNE}$ protein adducts, as evidenced by the green fluorescence in CTRL- $\mathrm{H}_{2} \mathrm{O}_{2}$-RHE (Figure 8a). Notably, a 35\% decrease in the fluorescence intensity of $4 \mathrm{HNE}$ protein adducts levels has been detected in the case of ETHO-CoQ10- $\mathrm{H}_{2} \mathrm{O}_{2}-\mathrm{RHE}$, suggesting that ETHO-CoQ10 are able to protect skin tissue after exposure to oxidative stress (Figure 8b). It is noteworthy that the antioxidant effect of CoQ10 has been exerted not only on the superficial SC but also in the deeper layers, as detectable by the inhibition of the fluorescence throughout the whole RHE portion, down to the stratum basale. It can be supposed that after application, ETHO-CoQ10 first pass through the upper SC, then they reach the deeper layers, confirming the mechanism of skin penetration previously described for ETHO [51,54]. Indeed, the ability of ethanol as a penetration enhancer in disturbing the organization of SC lipids, promotes the diffusion of the soft malleable vesicles in the deeper skin layers, where their fusion allows the transdermal release of the drug [51,54]. 
(a)

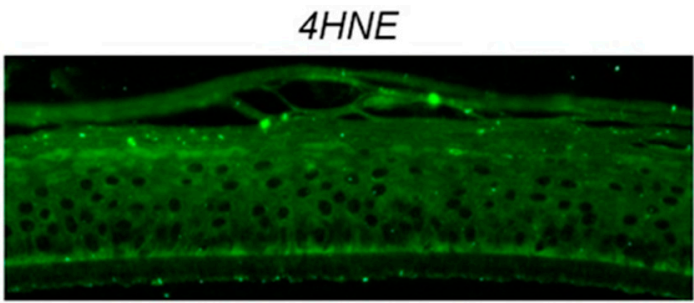

ETHO-COQ10-RHE

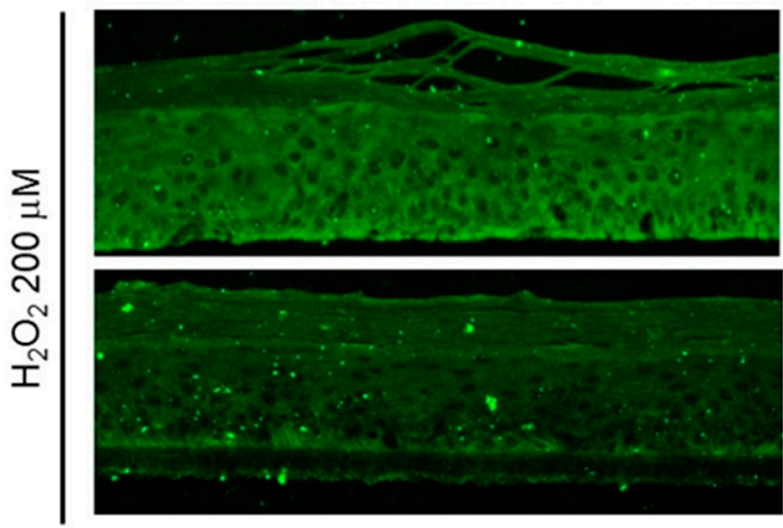

CTRL- $\mathrm{H}_{2} \mathrm{O}_{2}-\mathrm{RHE}$

ETHO-CoQ10- $\mathrm{H}_{2} \mathrm{O}_{2}-\mathrm{RHE}$

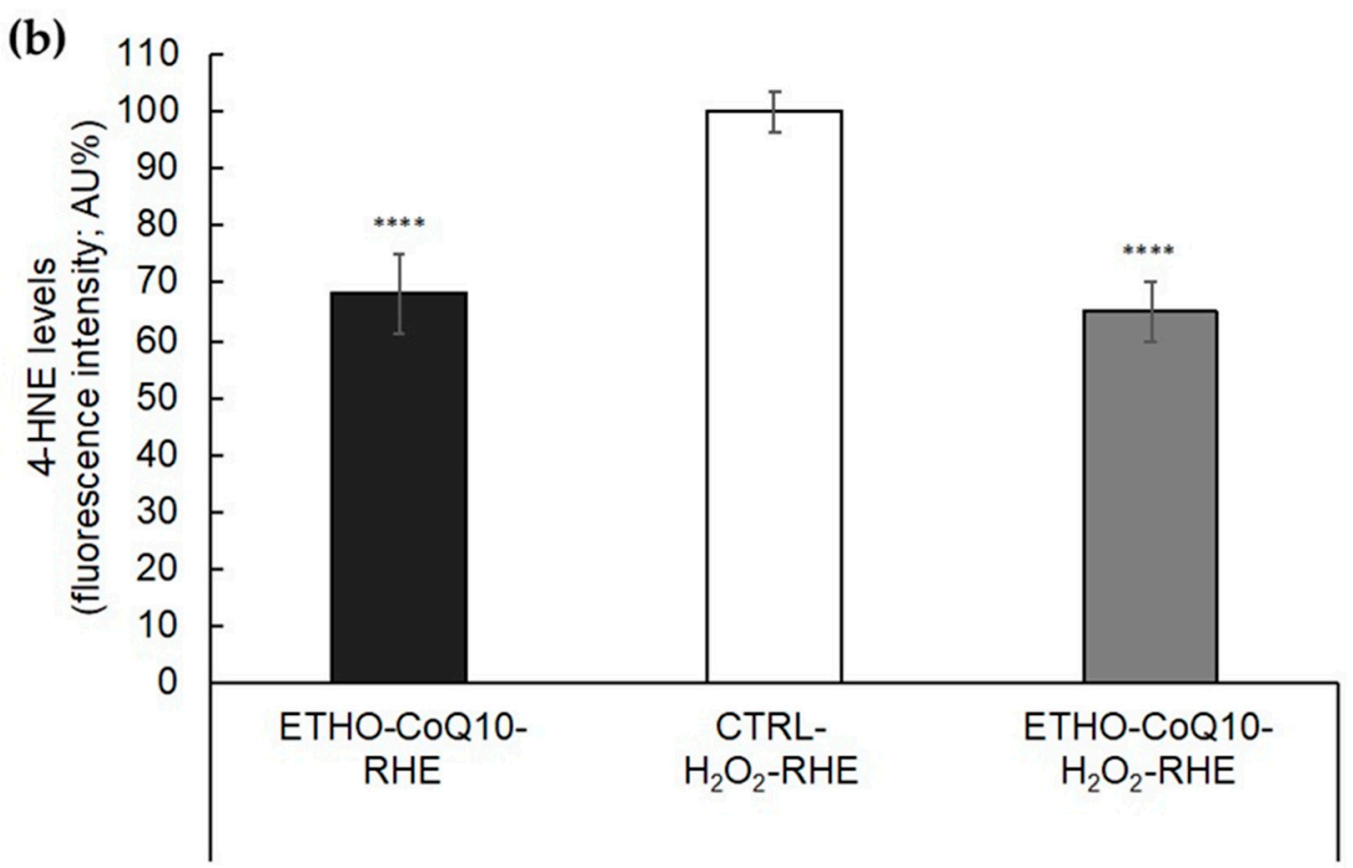

Figure 8. (a) Representative immunocytochemical images for $4 \mathrm{HNE}$ protein adducts in portions of RHE pretreated with ETHO-CoQ10 (ETHO-CoQ10- $\mathrm{H}_{2} \mathrm{O}_{2}-\mathrm{RHE}$ ) and compared to control RHE treated with ETHO-CoQ10 not exposed to $\mathrm{H}_{2} \mathrm{O}_{2}$ (ETHO-CoQ10-RHE), or to RHE exposed to $\mathrm{H}_{2} \mathrm{O}_{2} 200 \mu \mathrm{M}$ of $\mathrm{H}_{2} \mathrm{O}_{2}$ for $90 \mathrm{~min}$ (CTRL- $\mathrm{H}_{2} \mathrm{O}_{2}$-RHE). Images were taken at 40×. (b) Quantification of immunofluorescence staining for $4 \mathrm{HNE}$ after $\mathrm{H}_{2} \mathrm{O}_{2}$ exposure. Data were normalized with respect to CTRL- $\mathrm{H}_{2} \mathrm{O}_{2}-\mathrm{RHE}$ and expressed as arbitrary units \pm SD. ${ }^{* * *} p \leq 0.0001$ vs. CTRL.

\section{Conclusions}

The present investigation has demonstrated the suitability of ETHO as a transcutaneous delivery system for CoQ10. The preformulatory study has underlined the importance of size distribution analysis for selecting the composition of ETHO vesicles. SAXS and cryo-TEM evidenced the multilamellar structure of vesicles based on phosphatidylcholine and ethanol. 
Notably, due to their peculiar supramolecular organization, ETHO were able to increase the EC of CoQ10 and to better control its stability with respect to other nanosystems previously investigated in other studies, confirming the tremendous potential of ETHO vesicles for solubilization and delivery of lipophilic drugs. The composition and preparation modalities of ETHO described in this study could be applied to entrap molecules not only with antioxidant properties in order to improve their absorption and to delay their degradation.

Ex-vivo studies have corroborated the hypothesis of using ETHO as nanosystems for CoQ10 delivery through the skin. Indeed, TEM analyses confirmed the ETHO fibroblasts uptake, as well as their passage through the more complex model RHE. Furthermore, the decrease of fluorescence signal intensity down to the stratum basale corroborates the efficiency of ETHO as transdermal delivery systems, resulting as a promising vehicle for CoQ10 encapsulation. Remarkably, RHE can be considered reliable models to investigate the effect of topical formulation on skin; nevertheless, further in vivo studies will be required to evaluate not only the comparable antioxidant delivery against other carrier systems, but also the prolonged antioxidant effect of ETHO-CoQ10.

Author Contributions: Conceptualization, E.E. and G.V.; Methodology, E.E., G.V. and R.C.; Preparation of ethosome, M.S.; Characterization of ethosomes, M.S.; Discussion E.E.; Cryo-TEM analyses, M.D.; Discussion E.E.; SAXS analysis and discussion, P.M. and F.S.; In vitro and ex vivo experiments M.S., M.B., and R.P.; TEM analyses F.C.; In vitro and ex-vivo experiments discussion M.S. and G.V.; Original draft preparation, E.E. and G.V.; Writing and editing, E.E., R.C., M.S. and G.V. All authors have read and agreed to the published version of the manuscript.

Funding: This research was funded by the University of Ferrara (FIR 2019 and FAR 2019). Roxane Prieux and Giuseppe Valacchi are as part of the CITYCARE project which has received funding from the European Union's Horizon 2020 research and innovation program under the Marie Sklodowska-Curie grant agreement no. 765602.

Acknowledgments: We thank Diamond Light Source for access to beam-line B21 (SM21035-182) that contributed to SAXS results here presented.

Conflicts of Interest: The authors declare no conflict of interest.

\section{References}

1. Genova, M.L.; Lenaz, G. New developments on the functions of coenzyme Q in mitochondria. BioFactors 2011, 37, 330-354. [CrossRef] [PubMed]

2. Garrido-Maraver, J.; Cordero, M.D.; Oropesa-Ávila, M.; Fernández Vega, A.; De la Mata, M.; Delgado Pavón, A.; De Miguel, M.; Pérez Calero, C.; Villanueva Paz, M.; Cotán, D.; et al. Coenzyme Q10 therapy. Mol. Syndromol. 2014, 5, 187-197. [CrossRef] [PubMed]

3. Saini, R. Coenzyme Q10: The essential nutrient. J. Pharm. Bioallied Sci. 2011, 3, 466-467. [CrossRef] [PubMed]

4. Fotino, A.D.; Thompson-Paul, A.M.; Bazzano, L.A. Effect of coenzyme Q10 supplementation on heart failure: A meta-analysis. Am. J. Clin. Nutr. 2013, 97, 268-275. [CrossRef]

5. Singh, U.; Devaraj, S.; Jialal, I. Coenzyme Q10 supplementation and heart failure. Nutr. Rev. 2007, 65, 286-293. [CrossRef]

6. Hernández-Camacho, J.D.; Bernier, M.; López-Lluch, G.; Navas, P. Coenzyme Q10 supplementation in aging and disease. Front. Physiol. 2018, 9, 44. [CrossRef]

7. Folkers, K.; Hanioka, T.; Xia, L.-J.; McRee, J.T.; Langsjoen, P. Coenzyme Q10 increases T4/T8 ratios of lymphocytes in ordinary subjects and relevance to patients having the aids related complex. Biochem. Biophys. Res. Commun. 1991, 176, 786-791. [CrossRef]

8. Thapa, M.; Dallmann, G. Role of coenzymes in cancer metabolism. Semin. Cell Dev. Biol. 2020, 98, 44-53. [CrossRef]

9. Knott, A.; Achterberg, V.; Smuda, C.; Mielke, H.; Sperling, G.; Dunckelmann, K.; Vogelsang, A.; Krüger, A.; Schwengler, H.; Behtash, M.; et al. Topical treatment with coenzyme Q10-containing formulas improves skin's Q10 level and provides antioxidative effects: Topical Treatment with Coenzyme Q10. BioFactors 2015, 41, 383-390. [CrossRef]

10. Prahl, S.; Kueper, T.; Biernoth, T.; Wöhrmann, Y.; Münster, A.; Fürstenau, M.; Schmidt, M.; Schulze, C.; Wittern, K.-P.; Wenck, H.; et al. Aging skin is functionally anaerobic: Importance of coenzyme Q10 for anti aging skin care. Biofactors 2008, 32, 245-255. [CrossRef] 
11. Ashida, Y.; Yamanishi, H.; Terada, T.; Oota, N.; Sekine, K.; Watabe, K. CoQ10 supplementation elevates the epidermal CoQ10 level in adult hairless mice. Biofactors 2005, 25, 175-178. [CrossRef] [PubMed]

12. Rusciani, L.; Proietti, I.; Rusciani, A.; Paradisi, A.; Sbordoni, G.; Alfano, C.; Panunzi, S.; De Gaetano, A.; Lippa, S. Low plasma coenzyme Q10 levels as an independent prognostic factor for melanoma progression. J. Am. Acad. Dermatol. 2006, 54, 234-241. [CrossRef] [PubMed]

13. Hseu, Y.-C.; Ho, Y.-G.; Mathew, D.C.; Yen, H.-R.; Chen, X.-Z.; Yang, H.-L. The in vitro and in vivo depigmenting activity of Coenzyme Q10 through the down-regulation of $\alpha$-MSH signaling pathways and induction of Nrf2/ARE-mediated antioxidant genes in UVA-irradiated skin keratinocytes. Biochem. Pharmacol. 2019, 164, 299-310. [CrossRef] [PubMed]

14. Pegoraro, N.S.; Mattiazzi, J.; Da Silveira, E.F.; Azambuja, J.H.; Braganhol, E.; Cruz, L. Improved photostability and cytotoxic effect of coenzyme Q10 by its association with vitamin E acetate in polymeric nanocapsules. Pharm. Dev. Technol. 2018, 23, 400-406. [CrossRef] [PubMed]

15. Yue, Y.; Zhou, H.; Liu, G.; Li, Y.; Yan, Z.; Duan, M. The advantages of a novel CoQ10 delivery system in skin photo-protection. Int. J. Pharm. 2010, 392, 57-63. [CrossRef] [PubMed]

16. Gokce, E.H.; Korkmaz, E.; Tuncay-Tanrıverdi, S.; Dellera, E.; Sandri, G.; Bonferoni, M.C.; Ozer, O. A comparative evaluation of coenzyme Q10-loaded liposomes and solid lipid nanoparticles as dermal antioxidant carriers. Int. J. Nanomed. 2012, 7, 5109-5117. [CrossRef]

17. Wang, J.; Wang, H.; Xia, Q. Ubidecarenone-loaded nanostructured lipid carrier (UB-NLC): Percutaneous penetration and protective effects against hydrogen peroxide-induced oxidative stress on HaCaT cells. IJMS 2018, 19, 1865. [CrossRef]

18. Shaheen, M.A.; Elmeadawy, S.H.; Bazeed, F.B.; Anees, M.M.; Saleh, N.M. Innovative coenzyme Q10-loaded nanoformulation as an adjunct approach for the management of moderate periodontitis: Preparation, evaluation, and clinical study. Drug Deliv. Transl. Res. 2020, 10, 548-564. [CrossRef]

19. Wang, J.; Wang, H.; Zhou, X.; Tang, Z.; Liu, G.; Liu, G.; Xia, Q. Physicochemical characterization, photo-stability and cytotoxicity of coenzyme Q10-loading nanostructured lipid carrier. J. Nanosci. Nanotechnol. 2012, 12, 2136-2148. [CrossRef]

20. Nanjwade, B.K.; Kadam, V.T.; Manvi, F.V. Formulation and characterization of nanostructured lipid carrier of ubiquinone (coenzyme Q10). J. Biomed. Nanotechnol. 2013, 9, 450-460. [CrossRef]

21. Abdulbaqi, I.M.; Darwis, Y.; Khan, N.A.K.; Assi, R.A.; Khan, A.A. Ethosomal nanocarriers: The impact of constituents and formulation techniques on ethosomal properties, in vivo studies, and clinical trials. Int. J. Nanomed. 2016, 11, 2279-2304. [CrossRef] [PubMed]

22. Natsheh, H.; Vettorato, E.; Touitou, E. Ethosomes for dermal administration of natural active molecules. CPD 2019, 25, 2338-2348. [CrossRef] [PubMed]

23. Mahmood, S.; Mandal, U.K.; Chatterjee, B. Transdermal delivery of raloxifene $\mathrm{HCl}$ via ethosomal system: Formulation, advanced characterizations and pharmacokinetic evaluation. Int. J. Pharm. 2018, 542, $36-46$. [CrossRef] [PubMed]

24. Mishra, A.D.; Patel, C.N.; Shah, D.R. Formulation and optimization of ethosomes for transdermal delivery of ropinirole hydrochloride. Curr. Drug Deliv. 2013, 10, 500-516. Available online: http://www.eurekaselect. com/115015/article (accessed on 29 April 2020). [CrossRef]

25. Shen, L.-N.; Zhang, Y.-T.; Wang, Q.; Xu, L.; Feng, N.-P. Enhanced in vitro and in vivo skin deposition of apigenin delivered using ethosomes. Int. J. Pharm. 2014, 460, 280-288. [CrossRef]

26. Zhang, Y.-T.; Shen, L.-N.; Zhao, J.-H.; Feng, N.-P. Evaluation of psoralen ethosomes for topical delivery in rats by using in vivo microdialysis. Int. J. Nanomed. 2014, 9, 669-678. [CrossRef] [PubMed]

27. Choi, J.-H.; Cho, S.-H.; Yun, J.-J.; Yu, Y.-B.; Cho, C.-W. Ethosomes and transfersomes for topical delivery of ginsenoside Rhl from red ginseng: Characterization and in vitro evaluation. J. Nanosci. Nanotechnol. 2015, 15, 5660-5662. [CrossRef]

28. Bodade, S.S.; Shaikh, K.S.; Kamble, M.S.; Chaudhari, P.D. A study on ethosomes as mode for transdermal delivery of an antidiabetic drug. Drug Deliv. 2013, 20, 40-46. [CrossRef]

29. Yu, X.; Du, L.; Li, Y.; Fu, G.; Jin, Y. Improved anti-melanoma effect of a transdermal mitoxantrone ethosome gel. Biomed. Pharmacother. 2015, 73, 6-11. [CrossRef]

30. Tian, W.; Hu, Q.; Xu, Y.; Xu, Y. Effect of soybean-lecithin as an enhancer of buccal mucosa absorption of insulin. Bio Med. Mater. Eng. 2012, 22, 171-178. [CrossRef] 
31. Lachenmeier, D.W. Safety evaluation of topical applications of ethanol on the skin and inside the oral cavity. J. Occup. Med. Toxicol. 2008, 3, 26. [CrossRef]

32. Esposito, E.; Mariani, P.; Ravani, L.; Contado, C.; Volta, M.; Bido, S.; Drechsler, M.; Mazzoni, S.; Menegatti, E.; Morari, M.; et al. Nanoparticulate lipid dispersions for bromocriptine delivery: Characterization and in vivo study. Eur. J. Pharm. Biopharm. 2012, 80, 306-314. [CrossRef] [PubMed]

33. Pecora, R. Dynamic light scattering measurement of nanometer particles in liquids. J. Nanopart. Res. 2000, 2, 123-131. [CrossRef]

34. Barbosa, L.R.S.; Ortore, M.G.; Spinozzi, F.; Mariani, P.; Bernstorff, S.; Itri, R. The importance of protein-protein interactions on the $\mathrm{pH}$-induced conformational changes of bovine serum albumin: A small-angle $\mathrm{X}$-ray scattering study. Biophys. J. 2010, 98, 147-157. [CrossRef] [PubMed]

35. Touitou, E.; Dayan, N.; Bergelson, L.; Godin, B.; Eliaz, M. Ethosomes-Novel vesicular carriers for enhanced delivery: Characterization and skin penetration properties. J. Control. Release 2000, 65, 403-418. [CrossRef]

36. Esposito, E.; Sticozzi, C.; Ravani, L.; Drechsler, M.; Muresan, X.M.; Cervellati, F.; Cortesi, R.; Valacchi, G. Effect of new curcumin-containing nanostructured lipid dispersions on human keratinocytes proliferative responses. Exp. Dermatol. 2015, 24, 449-454. [CrossRef]

37. Valacchi, G.; Sticozzi, C.; Belmonte, G.; Cervellati, F.; Demaude, J.; Chen, N.; Krol, Y.; Oresajo, C. Vitamin C compound mixtures prevent ozone-induced oxidative damage in human keratinocytes as initial assessment of pollution protection. PLoS ONE 2015, 10, e0131097. [CrossRef]

38. Sguizzato, M.; Valacchi, G.; Pecorelli, A.; Boldrini, P.; Simelière, F.; Huang, N.; Cortesi, R.; Esposito, E. Gallic acid loaded poloxamer gel as new adjuvant strategy for melanoma: A preliminary study. Colloids Surf. B Biointerfaces 2020, 185, 110613. [CrossRef]

39. Dijkhoff, I.M.; Petracca, B.; Prieux, R.; Valacchi, G.; Rothen-Rutishauser, B.; Eeman, M. A Reliable Procedure to Cultivate Three-dimensional Human Epidermal Equivalents at Large Scale. Submitted in J Vis Exp.

40. Pecorelli, A.; Cervellati, F.; Belmonte, G.; Montagner, G.; Waldon, P.; Hayek, J.; Gambari, R.; Valacchi, G. Cytokines profile and peripheral blood mononuclear cells morphology in Rett and autistic patients. Cytokine 2016, 77, 180-188. [CrossRef]

41. Canella, R.; Benedusi, M.; Martini, M.; Cervellati, F.; Cavicchio, C.; Valacchi, G. Role of Nrf2 in preventing oxidative stress induced chloride current alteration in human lung cells. J. Cell Physiol. 2018, 233, 6018-6027. [CrossRef]

42. Sticozzi, C.; Belmonte, G.; Pecorelli, A.; Cervellati, F.; Leoncini, S.; Signorini, C.; Ciccoli, L.; De Felice, C.; Hayek, J.; Valacchi, G. Scavenger receptor B1 post-translational modifications in Rett syndrome. FEBS Lett. 2013, 587, 2199-2204. [CrossRef] [PubMed]

43. Fuller, B. Role of PGE-2 and other inflammatory mediators in skin aging and their inhibition by topical natural anti-inflammatories. Cosmetics 2019, 6, 6. [CrossRef]

44. Esposito, E.; Drechsler, M.; Huang, N.; Pavoni, G.; Cortesi, R.; Santonocito, D.; Puglia, C. Ethosomes and organogels for cutaneous administration of crocin. Biomed. Microdevices 2016, 18, 108. [CrossRef] [PubMed]

45. Puri, R.; Jain, S. Ethogel topical formulation for increasing the local bioavailability of 5-fluorouracil: A mechanistic study. Anticancer Drugs 2012, 23, 923-934. [CrossRef] [PubMed]

46. Zhaowu, Z.; Xiaoli, W.; Yangde, Z.; Nianfeng, L. Preparation of matrine ethosome, its percutaneous permeation in vitro and anti-inflammatory activity in vivo in rats. J. Liposome Res. 2009, 19, 155-162. [CrossRef]

47. Touitou, E.; Godin, B. Dermal drug delivery with ethosomes: Therapeutic potential. Therapy 2007, 4, 465-472. [CrossRef]

48. Spinozzi, F.; Paccamiccio, L.; Mariani, P.; Amaral, L.Q. Melting regime of the anionic phospholipid DMPG: New lamellar phase and porous bilayer model. Langmuir 2010, 26, 6484-6493. [CrossRef]

49. Andreozzi, P.; Funari, S.S.; La Mesa, C.; Mariani, P.; Ortore, M.G.; Sinibaldi, R.; Spinozzi, F. Multi- to unilamellar transitions in catanionic vesicles. J. Phys. Chem. B 2010, 114, 8056-8060. [CrossRef]

50. Spinozzi, F.; Ferrero, C.; Ortore, M.G.; De Maria Antolinos, A.; Mariani, P. GENFIT: Software for the analysis of small-angle X-ray and neutron scattering data of macro molecules in solution. J. Appl. Crystallogr. 2014, 47, 1132-1139. [CrossRef]

51. Godin, B.; Touitou, E. Ethosomes: New prospects in transdermal delivery. Crit. Rev. Ther. Drug Carr. Syst. 2003, 20, 63-102. [CrossRef] 
52. Zhang, Y.-T.; Shen, L.-N.; Wu, Z.-H.; Zhao, J.-H.; Feng, N.-P. Evaluation of skin viability effect on ethosome and liposome-mediated psoralen delivery via cell uptake. J. Pharm. Sci. 2014, 103, 3120-3126. [CrossRef] [PubMed]

53. Touitou, E.; Godin, B.; Dayan, N.; Weiss, C.; Piliponsky, A.; Levi-Schaffer, F. Intracellular delivery mediated by an ethosomal carrier. Biomaterials 2001, 22, 3053-3059. [CrossRef]

54. Jain, S.; Tiwary, A.K.; Sapra, B.; Jain, N.K. Formulation and evaluation of ethosomes for transdermal delivery of lamivudine. Aaps Pharmscitech 2007, 8, 249. [CrossRef]

55. Castro, J.P.; Jung, T.; Grune, T.; Siems, W. 4-Hydroxynonenal (HNE) modified proteins in metabolic diseases. Free Radic. Biol. Med. 2017, 111, 309-315. [CrossRef] [PubMed]

56. Takahashi, T.; Mine, Y.; Okamoto, T. Extracellular coenzyme Q10 (CoQ10) is reduced to ubiquinol-10 by intact Hep G2 cells independent of intracellular CoQ10 reduction. Arch. Biochem. Biophys. 2019, 672, 108067. [CrossRef] [PubMed]

57. Palmer, B.; DeLouise, L. Nanoparticle-enabled transdermal drug delivery systems for enhanced dose control and tissue targeting. Molecules 2016, 21, 1719. [CrossRef]

58. Prieux, R.; Eeman, M.; Rothen-Rutishauser, B.; Valacchi, G. Mimicking cigarette smoke exposure to assess cutaneous toxicity. Toxicol. Vitr. 2020, 62, 104664. [CrossRef]

(C) 2020 by the authors. Licensee MDPI, Basel, Switzerland. This article is an open access article distributed under the terms and conditions of the Creative Commons Attribution (CC BY) license (http://creativecommons.org/licenses/by/4.0/). 